\title{
Muscarinic and Nicotinic Synaptic Activation of the Developing Chicken Iris
}

\author{
Guillermo Pilar, Ramon Nuñez, ${ }^{a}$ lan S. McLennan, ${ }^{\mathrm{b}}$ and Stephen D. Meriney \\ The University of Connecticut, Department of Physiology and Neurobiology, Storrs, Connecticut 06268
}

The development of the mechanical characteristics of contraction and the pharmacology of synaptic activation in chick iris and ciliary body were examined from embryonic day 9 through posthatching. The ciliary ganglion-target muscle system has proven to be a useful model for both in vivo and in vitro studies of neuron-target interactions; one such interaction is involved in neuronal cell death, which in the ciliary ganglion occurs from Stage (St) 34 to 40 . To understand the mechanism by which cholinergic blocking agents prevent naturally occurring neuronal death in the chick ciliary ganglion (see the following paper, Meriney et al., 1987), it was necessary to determine the effect of these agents on synaptic transmission at target structures during the cell death period. Initially (St 34-36), iris muscle contractions are synaptically mediated via muscarinic ACh receptors (AChRs) on myoepithelial cells, which have the contractile and structural characteristics of smooth muscle. Close apposition of synaptic terminals, similar to that described for mature synapses, was observed on these myoepithelial cells. Subsequently (St 37), the striated muscle fibers that appear are activated by nicotinic receptors, although muscarinic AChRs are also present. Mechanically, this can be seen as gradually changing from a slow-onset contraction, elicited only by $\mathbf{3 0}$ $\mathrm{Hz}$ stimulation, to a fast-twitch response (St 37-44). Dilator fibers that develop later in the iris (at about St 39) also possess nicotinic and muscarinic receptors. The cillary body musculature, although not extensively studied, also appears to have dual cholinergic activation during development. The mature iris has predominately striated muscle fibers that have both junctional nicotinic and muscarinic (mostly extrajunctional) AChRs. The dual presence of both receptor types in the same muscle fiber was confirmed with intracellular recordings, in which only the initial portion of the ACh-elicited depolarization was sensitive to alpha bungarotoxin $(\alpha B T X)$. In addition, specific muscarinic binding sites were

\footnotetext{
Received Apr. 21, 1986; revised June 8, 1987; accepted June 11, 1987.

We thank L. Landmesser and D. B. Gray for critical evaluation of the manuscript, and S. Putnam for assistance in its preparation. This work was supported by NIH 10338, NSF-BNS 8410581, a MDA Fellowship to R.N., a C. J. Martin Fellowship (NRC, Australia) to I.S.M., and The University of Connecticut Research Foundation.

Correspondence should be addressed to Dr. Guillermo Pilar, The University of Connecticut, Department of Physiology' and Neurobiology, 75 N. Eagleville Road, Room 416, Storrs, CT 06268.

a Present address: 11 Principal Ave., Chahuites, Oaxaca, Mexico.

- Present address: Department of Behavioural Biology, Research School of Biological Sciences, The Australian National University, Canberra City, A.C.T. 2601, Australia.

' Present address: Jerry Lewis Neuromuscular Research Center, UCLA School of Medicine, 700 Westwood Plaza, Los Angeles, CA 90024.
}

Copyright $(\subset) 1987$ Society for Neuroscience $0270-6474 / 87 / 123813-14 \$ 02.00 / 0$ described in the developing, as well as in the mature, iris. The developing chick iris was also shown to contract directly in response to light, this response disappearing after hatching. This unique dual-receptor pharmacology (nicotinicmuscarinic) and light response of a striated muscle may be due to the neural crest origin of these cells.

This paper describes the development of chicken iris muscle innervation and synaptic activation. This investigation was undertaken to better understand the competition for survival that occurs among the innervating motoneurons of the ciliary ganglion. The iris and ciliary ganglion have been extensively used by us (Pilar and Vaughan, 1969a, 1971; Pilar and Landmesser, 1972; Pilar et al., 1981) and by other investigators (Chiappinelli and Giacobini, 1978; Narayanan and Narayanan, 1981) in a number of studies on the reciprocal interactions between neurons and their targets.

It has long been known that bird iris muscle fibers are striated (Geberg, 1884). In previous studies of the innervation of adult pigeon iris muscle, we demonstrated that these multiply innervated striated cells respond to an action potential with a "twitch" response (similar to that of skeletal "twitch" muscles), and to a maintained depolarization with a sustained contraction (similar to that of slow muscle fibers) (Pilar and Vaughan, 1969a). This ability of the iris to respond with both a phasic and tonic response underlies the iris's tetanic contractile response to highfrequency ciliary nerve stimulation. Initially, the muscle generates action potentials, but these eventually fail and junction potentials maintain a depolarization that sustains the contraction (Pilar and Vaughan, 1969b). This is unlike skeletal "twitch" fibers, which rely on action potential generation in the muscle fiber for contraction. Ultrastructurally, the pigeon iris has been shown to resemble "twitch" muscles, but the sparseness of the sarcoplasmic reticulum in the A-band is a characteristic of slow tonic muscle fibers (Pilar and Vaughan, 1971). Cholinergic neuromuscular transmission in the adult avian iris is nicotinic (Pilar and Vaughan, 1969a). The muscle fibers are organized in 2 functionally different muscles, a constrictor and a dilator (Durand, 1893; Van Oehme, 1969), the latter muscle being absent in pigeon (G. Pilar, unpublished observations).

Until recently, the embryological origin of the iris has been a matter of controversy (Brini et al., 1964; Gabella and Clarke, 1983; Ferrari and Koch, 1984a, b). It has been proposed that the iris forms from myoepithelial cells (smooth muscle-type cells) derived from elements migrating from the inner retinal layer (Romanoff, 1960). At Stage (St) 31-32, this epithelial cell layer gives rise to an everted zone of cells that expands and migrates into the overlying mesenchyme of the iris anlage in the anterior chamber of the eye (Ferrari and Koch, 1984a). Neuromuscular transmission begins soon after the first myoepi- 
thelial cells arrive at the iris primordium (Landmesser and Pilar, 1974; Pilar et al., 1980, 1981) and some evidence suggests that these cells are the precursors of the striated muscle cells.

To further study the dependence of neuronal survival on the target, we attempted to disrupt pharmacologically the initial synaptic transmission in the iris, ciliary, and choroid muscles in experiments similar to those performed by Pittman and Oppenheim (1978) in the lumbosacral spinal cord, where injection of alpha bungarotoxin ( $\alpha$ BTX) into the egg rescued spinal motoneurons destined to die. To our surprise, when $\alpha$ BTX was injected into the egg at St 34, it failed to block iris transmission, which was instead blocked by atropine, indicating that the initial synaptic transmission was mediated via muscarinic receptors. There are 2 pharmacologically and physiologically distinct peripheral ACh receptors (Goodman and Gilman, 1975). Nicotinic AChRs are observed at skeletal neuromuscular junctions (NMJ) and have been well-characterized using radiolabeled binding with $\alpha$ BTX. Muscarinic AChRs have been studied biochemically at the smooth $\mathrm{NMJ}$ of the ileum, using radiolabeled tritiated quinuclidinyl benzylate $\left({ }^{3} \mathrm{H}-\mathrm{QNB}\right.$ ) (Yamamura and Snyder, 1974).

The apparently initially muscarinic transmission prompted the present investigation of the developing chick iris. However, many other features of this tissue make this study interesting from a more general standpoint. Since this preparation is used extensively in both in vivo and in vitro analyses, it is important to establish the development of various characteristics in this tissue, such as the novel existence of both muscarinic and nicotinic AChRs in the same muscle cells. In addition, to understand the dependence of developing ciliary ganglion neurons on their targets, it is important to determine when the muscle's dual innervation occurs, what tissues compose the target, what types of contacts are initially established, and what are the response characteristics of synaptic activation.

In this paper, we describe both AChR types (nicotinic and muscarinic) in the same muscle cells-when these receptors appear and what type of contractile responses are elicited by their activation in the developing and mature muscle fibers in both the dilator and the constrictor iris. The muscle cells are initially smooth, but later, by hatching, most of the constrictor cells are striated. These cells also show a contractile response to light. Brief reports of these findings have been presented (Vaca et al., 1980; Nuñez et al., 1980, 1982).

\section{Materials and Methods}

Animals. White Leghorn chick embryos were incubated in a forceddraft incubator until the desired stage was reached (Hamburger and Hamilton, 1951). Albino chickens were used for the determination of ${ }^{3} \mathrm{H}-\mathrm{QNB}$ binding, and posthatching chicks were obtained from The University of Connccticut Poultry Science Department.

Iris muscle contractions. Two methods of mechanical recording were used to study the innervation of the iris muscles. For both methods, the iris preparation was placed in a Lucite chamber, where the tissue was superfused with oxygenated Tyrode's solution. Most of the experiments were performed with red illumination or with low, diffuse white light to avoid contaminating the nerve-evoked response with the lightinduced response (described later).

After the ciliary nerves were dissected out together with a ring of sclera containing the iris and ciliary body muscles, pupillomorphic measurements of iris contractions were made. The lens was removed, and the sclera was pinned to the Sylgard bottom of the recording chamber. Light was shone on the sample from beneath, and following nerve stimulation, we photographed changes in pupil diameter with a $35 \mathrm{~mm}$ camera attached to a dissecting microscope. The pupil area, after normalization for variations in iris size, was used as an index of the con- tractile response. The resting area of the pupil was defined as $0 \%$ contraction, and the contraction after incubation in $100 \mathrm{mM} \mathrm{K}^{+}$was defined as $100 \%$ contraction. For most experiments, values for iris closure were expressed as a percentage of the $100 \mathrm{~mm} \mathrm{~K} \mathrm{~K}^{+}$-induced contraction. The degree of contraction was calculated as follows:

$$
\frac{\text { Resting pupil area }- \text { experimental pupil area }}{\text { Resting pupil area }-100 \mathrm{mM} \mathrm{K}^{+} \text {pupil area }} \times 100 \text {. }
$$

"Isometric" iris responses were obtained with an electromechanical strain gauge. The iris preparation was dissected as described above, and the end of the iris ring opposite the apparent emergence of the ciliary nerves was lifted from the sclera and attached to the force transducer. This transducer was mounted in a micromanipulator, allowing adjustment of the length of the muscle for optimal-response recording. The other end of the iris was left attached to the sclera, which was firmly pinned to the Sylgard bottom of the chamber. The force transducer was calibrated and responded linearly at between 1 and $200 \mathrm{mg}$ of tension. The output of the transducer was displayed on a Brush ink recorder.

The ciliary nerves were stimulated with single or repeated pulses through suction electrodes. Extracellular recordings of iris muscle electrical activity were made with small suction electrodes carefully placed in contact with the muscle.

Intracellular electrophysiology. Intracellular records were obtained with conventional $50-80 \mathrm{M} \Omega$ glass microelectrodes filled with $3 \mathrm{M} \mathrm{KCl}$ and viewed on an oscilloscope via a unity gain negative-capacity preamplifier. An active bridge circuit in the amplifier allowed simultaneous current injection and voltage measurements.

Solutions and drugs. Drugs were added to the Tyrode's solution bathing the preparation, and their effects on the iris were observed at regular intervals. Antagonist drugs were added $30 \mathrm{~min}$ before agonists. Drug washout pcriods werc continucd until the recorded tension, or pupil diameter, was at control levels. Following washout periods, the preparation was allowed to rest for $30 \mathrm{~min}$ before the next drug application.

For most of the chemicals, the dose used was determined from doseresponse curves obtained prior to experimentation. Concentrations used were twice the dose necessary to produce the maximum effect.

Tyrode's solution of the following composition was used: $\mathrm{NaCl}, 134$ $\mathrm{mm} ; \mathrm{KCl}, 3 \mathrm{~mm} ; \mathrm{NaHCO}^{3}, 20 \mathrm{~mm} ; \mathrm{CaCl}_{2}, 3 \mathrm{~mm} ; \mathrm{MgCl}_{2}, 1 \mathrm{~mm}$; glucose, $12 \mathrm{~mm}$. Calcium was omitted in some experiments. In the $100 \mathrm{~mm} \mathrm{~K}^{+}$ solution, $\mathrm{Na}^{+}$was replaced by $\mathrm{K}^{+}$in the Tyrode's solution. ACh, atropine sulfate, and $\alpha$ BTX were obtained from Sigma Chemical Co. (St. Louis, $\mathrm{MO}$ ). Prostigmine and QNB (generously provided by Dr. P. Sorter) were obtained from Roche (Nutley, NJ).

Electron microscopy. Irises, St 35, 36, 371/2,39, 40, and 45, and 2 and $10 \mathrm{~d}$ after hatching, were fixed in $2 \%$ phosphate-buffered glutaraldchydc ( $\mathrm{pH} 7.3$ ) for 2-3 hr. Iris muscle geometry was maintained during this fixation by pinning the muscle to small pieces of cardboard. Specimens were postfixed overnight in $1 \%$ osmium tetroxide in phosphate buffer at $4^{\circ} \mathrm{C}$. Irises were oriented during embedding in Epon such that transverse and longitudinal thin sections could be made with an LKB ultramicrotome. Thin sections were mounted on $\$ 200$ mesh grids and on carbon-coated slot grids (allowing the observation and photography of large areas of the iris). Sections were stained with $2 \%$ uranyl acetate and $1.5 \%$ lead citrate prior to being viewed with a Phillips 300 electron microscope. The large sample of electron micrographs (high-magnification prints and low-power montage reconstructions) allowed a fair reconstruction of the morphological changes during development. In this paper, the characteristics of the contractile elements will be emphasized. $\Lambda$ structural study of the innervation has already been published (Narayanan and Narayanan, 1981; Pilar et al., 1981).

${ }^{3} \mathrm{H}$-QNB binding. The melanin pigment within the epithelium covering the iris is known to bind muscarinic drugs with high capacity but low affinity (Kloog et al., 1979). In the chicken iris, this low-affinity binding is much greater than, and masks, the high-affinity binding, even at low concentrations of ${ }^{3} \mathrm{H}-\mathrm{QNB}$ (unpublished observations). Therefore, all studies reported here were done on albino chickens, and, as an added precaution, the pigment epithelium layer was removed from the iris by gently rubbing the iris internal surface with a cotton bud. This procedure did not damage the muscle, and groups of isolated irises were homogenized in $200 \mu \mathrm{l}$ of $50 \mathrm{~mm}$ sodium phosphate at $\mathrm{pH} 7.4$. The number of irises in each group was 5 each for $\mathrm{St} 37$ embryos (embryonic day 11 ) and 1-d-posthatch (dph) chicks, 3 for 2-week-old chickens, and 1 for adult chickens.

Total binding was measured in duplicate tubes containing $50 \mu \mathrm{l}$ of 
sample, $1 \mathrm{~nm}{ }^{3} \mathrm{H}-\mathrm{QNB}(40.2 \mathrm{Ci} / \mathrm{mmol})$, and $50 \mathrm{~mm}$ sodium phosphate $(\mathrm{pH} 7.4)$ in a total volume of $100 \mu \mathrm{l}$. Nonspecific binding was measured by the inclusion of $1 \mu \mathrm{M}$ QNB into the tube. The tubes were incubated at $37^{\circ} \mathrm{C}$ for $30 \mathrm{~min}$, followed by filtration through Whatman $\mathrm{GF} / \mathrm{B}$ glass fiber filters. The filters were rinsed 5 times with $5 \mathrm{ml}$ of phosphate buffer and placed in scintillation vials. Then $100 \mu \mathrm{l}$ of protosol and $10 \mathrm{ml}$ of scintillation fluid were added to each vial. The vials were kept at $25^{\circ} \mathrm{C}$ overnight and the radioactivity was measured in a liquid scintillation counter. The counts were corrected for quenching by a channel ratio program. The specific binding was calculated by subtracting the nonspecific binding from the total binding. Protein content was determined by the method of Lowry et al. (1951), using chicken egg albumin as the standard.

\section{Results}

\section{Mechanical responses of the iris constrictor during} development

The tension recorded in the iris muscle during development is illustrated in Figure 1. At St 36, repetitive nerve stimulation at $30 \mathrm{IIz}$ caused a slowly developing contracture, elicited $1.2 \mathrm{scc}$ after the initiation of the electrical train and lasting beyond the termination of stimulation (Fig. $1 a$ ). This long and protracted response, characterized by slow rise and decay times, is similar to responses obtained in smooth muscles. Single-shock stimulation did not evoke a response (Fig. 1A).

Twenty-four hours later ( $\mathrm{St} 37$ ), single-shock stimulation of the ciliary nerves elicited a small twitch response (Fig. $1 B$ ), and the slow component of the tetanic response was preceded by a

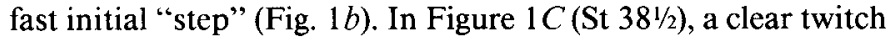
was evoked by single stimulation, and the initial response during tetanic stimulation quickly reached a plateau, but was still followed by a long contracture outlasting the stimulation (Fig. 1c). Similar recordings could be obtained until St 43 (Fig. 1d), with progressively smaller slow contractions persisting after the tetanic plateau. By $7 \mathrm{dph}$ the tetanic contracture had fast rise and decay phases (Fig. 1e), and the twitch had a fast time course (Fig. 1E).

These mechanical recordings are suggestive of 2 different contractile responses, a slow response similar to that seen in smooth muscle, and a fast response similar to that scen in striated muscle contraction. In addition, these 2 types of contractions did not develop simultaneously. The "smooth muscle" contracture developed first, followed by the "striated muscle" response, which, after hatching, represented the most prominent component of the output of the iris.

\section{$A C h$ receptor activation of "smooth" and "striated" muscle responses}

In the adult iris, neuromuscular transmission is mediated by ACh released from ciliary nerve terminals, which binds to nicotinic ACh receptors (AChRs) in the iris muscle (Pilar and Vaughan, 1971; Chiappinelli and Giacobini, 1978). Figure 2 demonstrates that stimulation $(75 \mathrm{~Hz})$ of the adult ciliary nerves resulted in a tetanic contraction that was not affected by atropine (Fig. $2 B$ ), but was blocked by the addition of $\alpha \mathrm{BTX}$ to the chamber (Fig. 2C).

As stated in the introduction, it was surprising to find that the iris muscle response in the St 36 embryonic chick was not affected by $\alpha$ BTX. The muscarinic nature of the receptors involved in this initial contractile response is shown in Figure 3 , $A, C$ (controls). As illustrated in Figure 1, repetitive stimulation of ciliary nerves caused a slow contracture, which was blocked when QNB (0.05 nM) (Fig. $3 D)$ or atropine $(0.2 \mu \mathrm{M})$ (not shown) was added to the perfusate. In another preparation (Fig. $3 B$ ), it

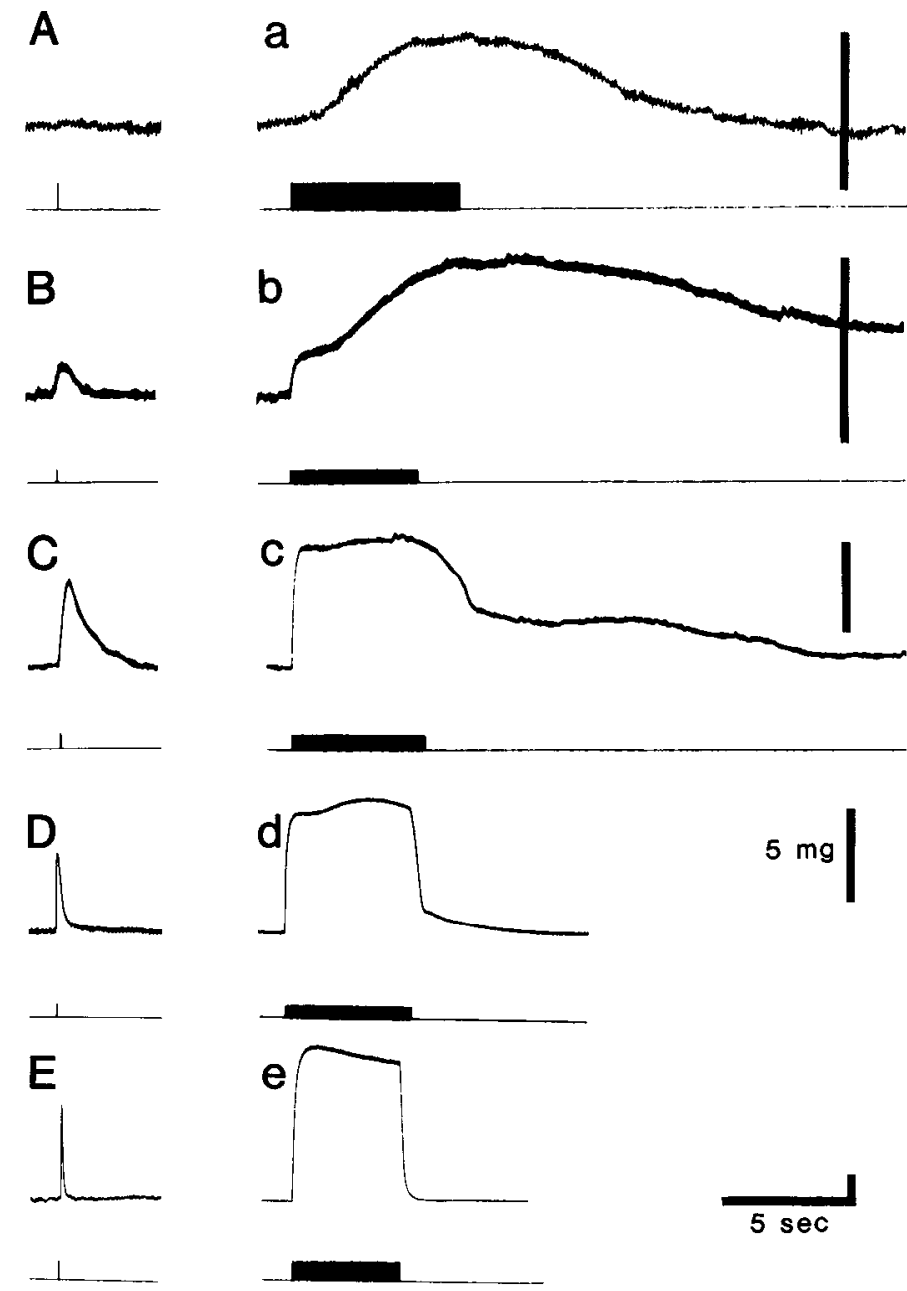

Figure 1. Developmental time course of twitch $(A-E)$ and tetanic $(a-$ e) contractions recorded in the iris muscle after nerve stimulation $(30$ $\mathrm{Hz}$ ). $A$, St 36 . There is no twitch response, and the tetanic contraction is of slcw onset and decay. $B$, St 37 . A small twitch response is apparent, and the slow component of the tetanic contraction is preceded by a fast "step" response. $C, \mathrm{St} 38.5$. A strong twitch response is recorded, and the tetanic contraction begins with a fast-rising plateau, followed by a slowly decaying contraction. $D, \mathrm{St} 41$. The twitch response becomes faster, and the tetanic response is dominated by a fast plateau contraction, although a small, slow component persists. $E$, Seven days posthatch (dph). A fast-twitch response, as weicas a fast rise and decay phase of the tetanic response, characterizes iris contractions through adulthood. All vertical calibrations, $5 \mathrm{mg}$.

was shown that $\alpha \mathrm{BTX}(1 \mu \mathrm{g} / \mathrm{ml})$ had no effect on the synaptic activation of the muscle.

Therefore, we attempted to pharmacologically dissociate the 2 distinct components of the iris rauscle response seen at intermediate stages (Fig. $1, B-D$ ). Figure $4, C, D$, shows that the initial fast component of a St $38 \frac{1}{2}$ iris was blocked by $\alpha$ BTX, leaving the slow component unaffected, while application of atropine selectively abolished the slow contracture (Fig. 4, $A$, $B)$. This provides convincing evidence for dual-receptor activation of the developing iris muscle.

The time course of these changes in the mode of muscle activation during development is summarized in Figure 5. In this graph, the iris contractures elicited by tetanic nerve stimulation under control conditions (Fig. 5, open bars) and in the presence of nicotine (dashed bar) or muscarine (stippled bar) 

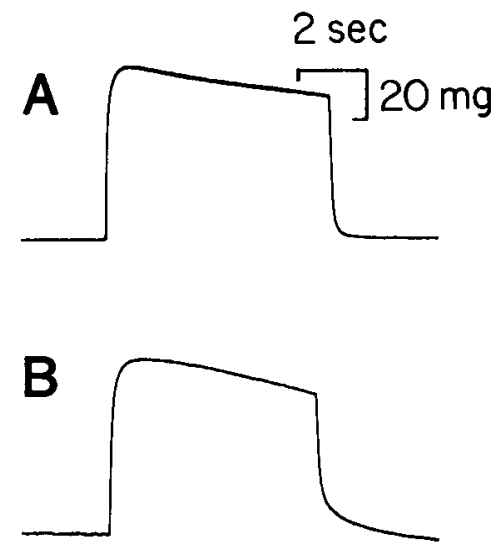

C
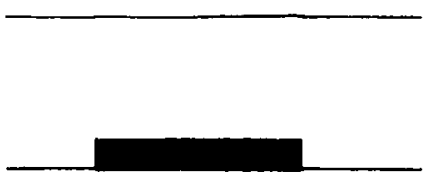

Figure 2. Effects of atropine and $\alpha \mathrm{BTX}$ on adult (>6-month-old) bird iris muscle contractions after $75 \mathrm{~Hz}$ nerve stimulation. $A$, Control. $B$, Atropine $(0.2 \mu \mathrm{M})$ does not significantly change the tetanic contraction. $C, \alpha \operatorname{BTX}(1 \mu / \mathrm{ml})$ completely blocks the tetanic contraction.

are shown. At $\mathrm{St} 36$, synaptic activation was unchanged when $\alpha \mathrm{BTX}$ was added to the bath and blocked after atropine or QNB administration (Fig. $5 A$ ), indicating predominantly muscarinic activation. However, synaptic activation begins even earlier ( $\mathrm{St}$ $34 \frac{1}{2}$ ), shortly after myoblast precursors migrate into the iris anlage, where ciliary nerves are already waiting. Owing to tissue compliance and insufficient sensitivity of the recording system,
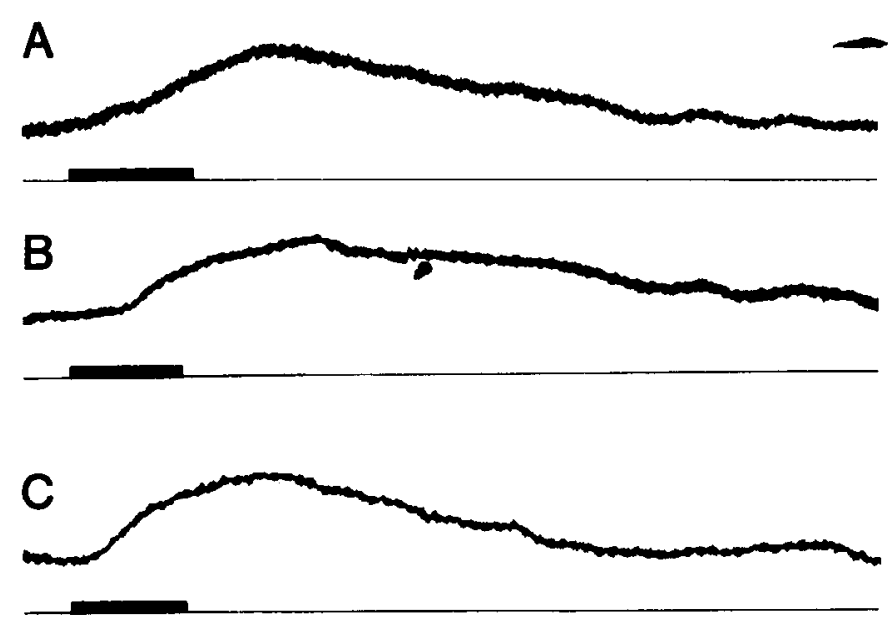

D
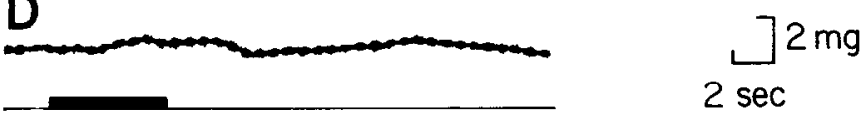

Figure 3. Effects of $\alpha \mathrm{BTX}$ and atropine on St 36 iris muscle contractions after nerve stimulation $(30 \mathrm{~Hz})$. $A$, Control tetanic contraction. $B$, $\alpha$ BTX $(1 \mu \mathrm{g} / \mathrm{ml})$ does not influence the tetanic contraction. $C$, Control tetanic contraction. $D$, Atropine $(0.2 \mu \mathrm{M})$ completely blocks the generation of tension after tetanic nerve stimulation.
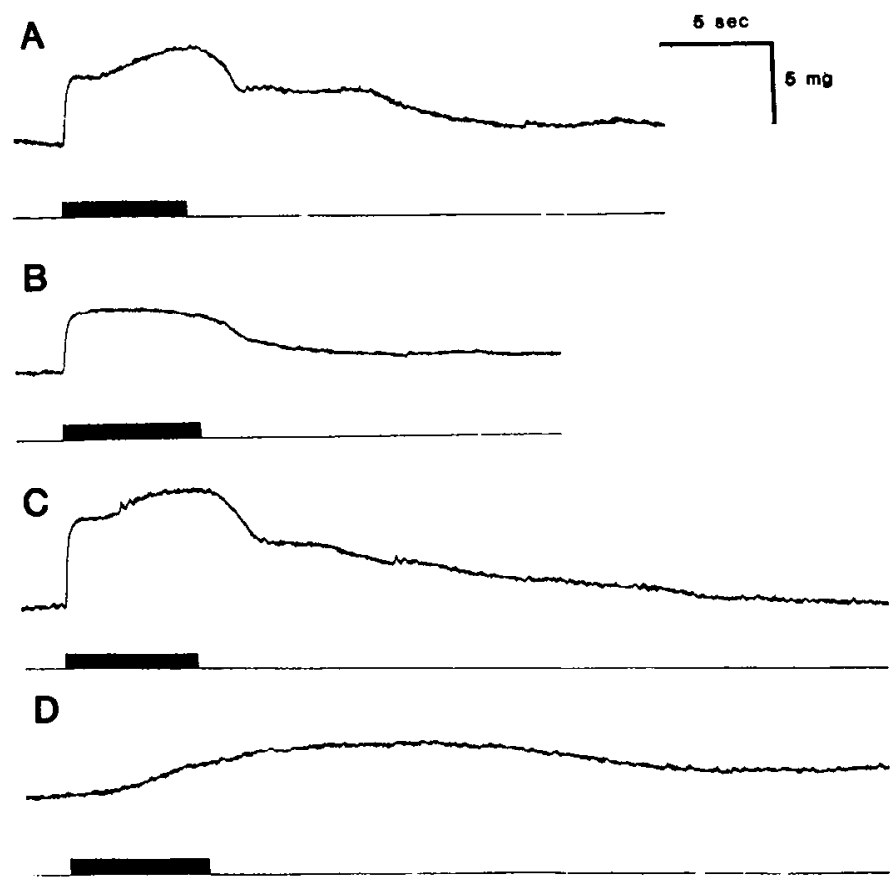

Figure 4. Effects of atropine and $\alpha \mathrm{BTX}$ on St 38.5 iris muscle contractions after nerve stimulation $(30 \mathrm{~Hz}) . A$, Control tetanic contraction. $B$, Atropine $(0.2 \mu \mathrm{M})$ blocks only the slow component of the contraction. $C$, Control tetanic contraction. $D, \alpha \mathrm{BTX}(1 \mu \mathrm{g} / \mathrm{ml})$ blocks only the initial fast plateau of the contraction.

mechanical responses could not be obtained at this stage ( $\mathrm{St}$ $34 \frac{1}{2}$ ), but movement in response to nerve stimulation was visually detected, as previously reported (Landmesser and Pilar, 1974), and this was blocked by QNB. By St 381/2, half of the total response was mediated by muscarinic receptors, while the remainder was mediated by nicotinic synaptic activation (Fig. $5 B$ ). At later stages (Fig. $5 C$ ), the mechanical response to nerve stimulation was mediated predominantly by nicotinic receptors.

The dual activation of the iris can also be demonstrated in the intact iris, using the pupillomorphic technique. These data complement those presented above, but allow the recording of the electrical activity associated with the mechanical response, and observation of the function of the iris and ciliary body fibers in a physiological context. In Figure 6 are a sample of photographs taken during the perfusion of drugs and electrical stimulation of ciliary nerves in an iris isolated at St 43. Figure $6 \mathrm{~A}$ shows a control pupil at rest. Maximal tetanic stimulation (50 $\mathrm{Hz}$ ) of the ciliary nerves reduced the pupillary area by about $66 \%$ (Fig. 6B). Atropine partially blocked this tetanic contraction $(59 \%$ reduction in pupillary area) (Fig. $6 \mathrm{C}$ ), which was completely abolished when $\alpha \mathrm{BTX}$ and atropine were both added to the superfusate (Fig. 6D). In another preparation (Fig. $6 a$, control), $\alpha$ BTX was applied to the tetanically stimulated iris (Fig. $6 c$ ) and partially blocked the pupillary closure (only $47 \%$ closure versus $63 \%$ control tetanic closure; Fig. $6 b$ ). Although the nicotinic $\mathrm{ACh}$ receptors were blocked by $\alpha \mathrm{BTX}, \mathrm{ACh}$ perfusion caused a decrease in pupil size (Fig. $6 d$ ) equal to that seen in the initial tetanic stimulation (Fig. 6b). This further demonstrates the existence of 2 different modes of cholinergic activation.

Using suction electrodes, we observed the electrical responses accompanying such muscle contraction. The upper record in Figure $7 A$ shows the extracellular compound action potential 

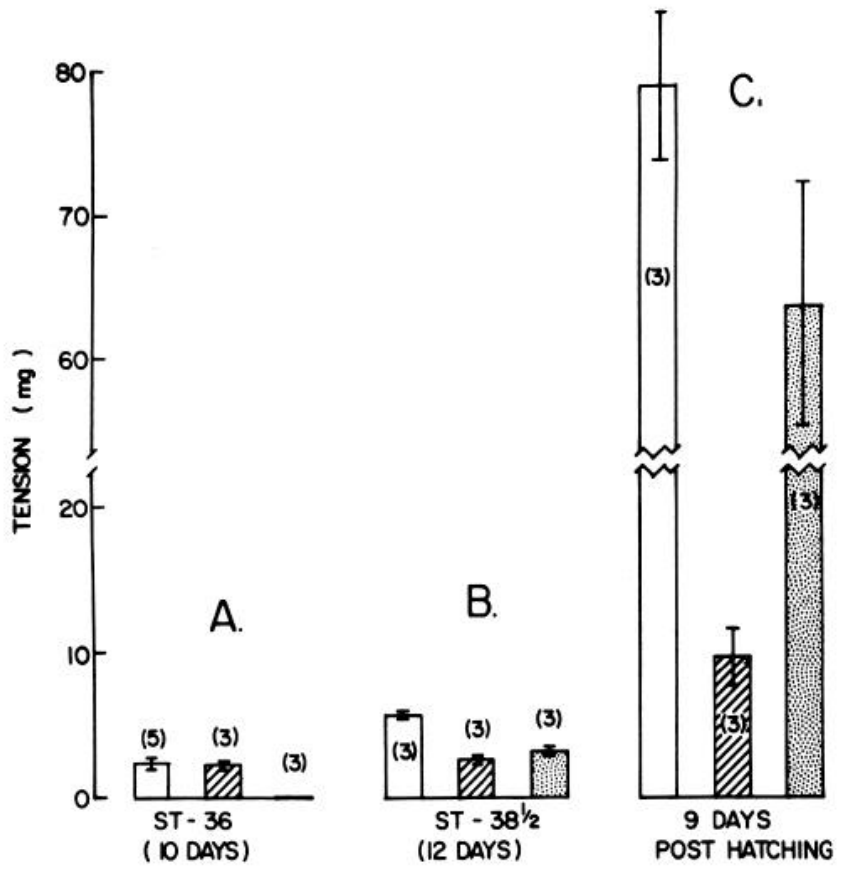

recorded in a St 43 iris muscle after single electrical pulse stimulation of the ciliary nerves. Figure $7 a$, lower trace shows the response recorded in the ciliary body muscle. Although atropine partially blocked the mechanical tetanic responses (Fig. $6 B$ ), the electrical responses remained essentially unchanged (Fig. $7 B$, upper and lower records), as would be expected if the action potentials were elicited by nicotinic receptors, probably initiated only in the striated muscle fibers (see also the characterization of the contractile elements of the iris, and Pilar and Vaughan, 1969a).

\section{$\leftarrow$}

Figure 5. Developmental changes in the proportion of muscarinic and nicotinic receptors mediating nerve-induced contraction. The open, striped, and stippled columns represent iris tension generated in control, $\alpha$ BTX-, and atropine-treated preparations, respectively. $A$, At the earliest stage recorded, $\alpha$ BTX added to the bathing solution (striped column) did not change the tension generated, whereas atropine (stippled column) eliminated the response. $B$, Iris contraction decrease caused by $\alpha$ BTX (striped column) indicates that the neuromuscular response is partially mediated by nicotinic receptors. $C$, Illustration of the large reduction in tension produced by the nicotinic antagonist (striped column) in contrast to the small decrement in tension produced by the muscarinic antagonist (stippled column). In this and in other figures, vertical lines indicate mean $\pm \mathrm{SE}$.
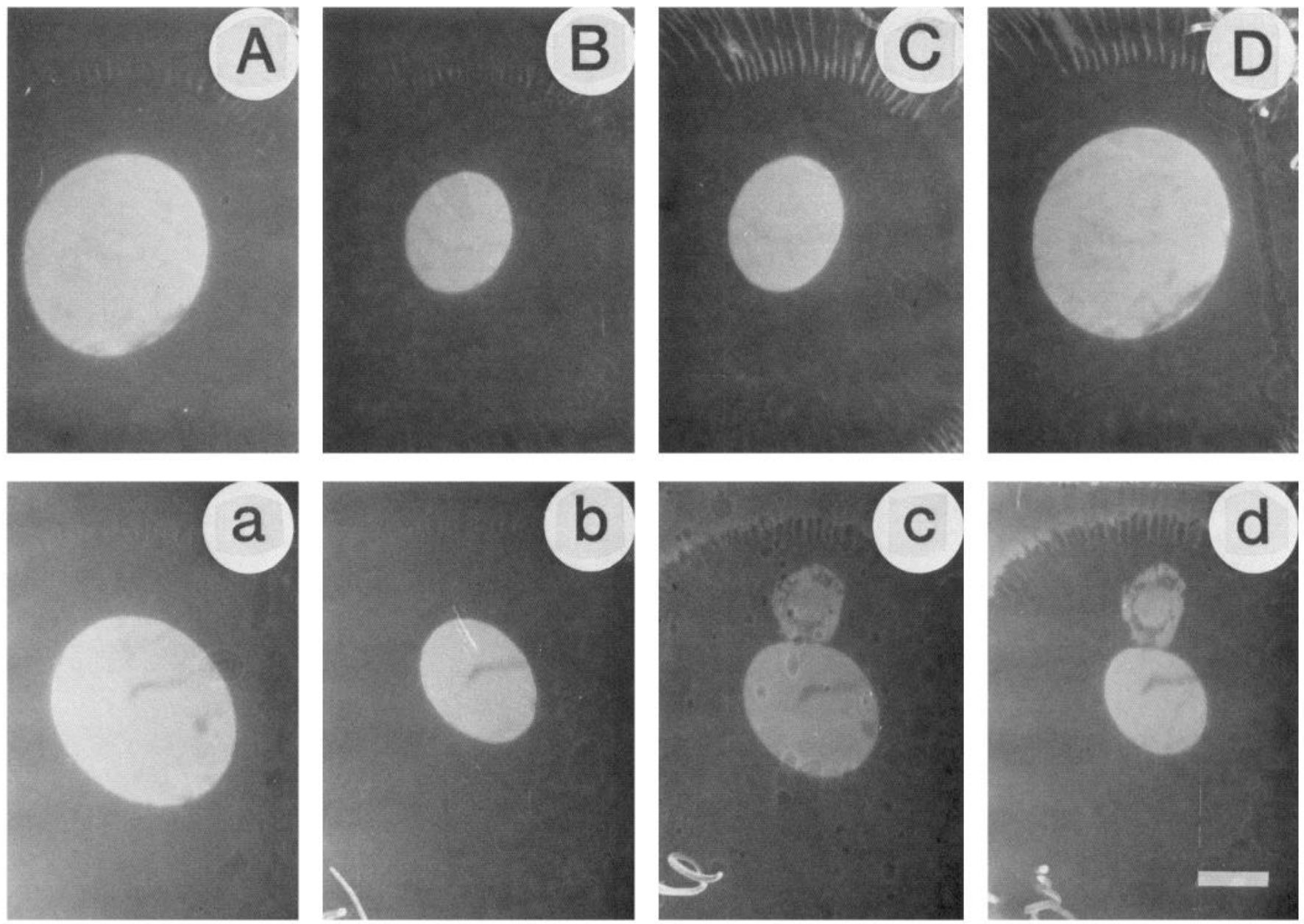

Figure 6. Pupillomorphic analysis of iris contractions at St 43. A, Control relaxation. B, Control tetanus (50 Hz). C, Tetanic contraction after atropine $(0.5 \mu \mathrm{M})$ administration is less than the control tetanic contraction. $D$, Tetanic stimulation after atropine $(0.5 \mu \mathrm{M})$ and $\alpha \mathrm{BTX}(1 \mu \mathrm{g} / \mathrm{ml})$ administration does not result in any contraction. $a$, Control relaxation. $b$, Control tetanus $(50 \mathrm{~Hz}) . c$, Tetanic contraction after $\alpha \mathrm{BTX}(1 \mu \mathrm{g} / \mathrm{ml})$ administration is less than control tetanic contraction. $d$, ACh-induced contraction of the $\alpha$ BTX-poisoned preparation is at least as strong as the control tetanic contraction. 


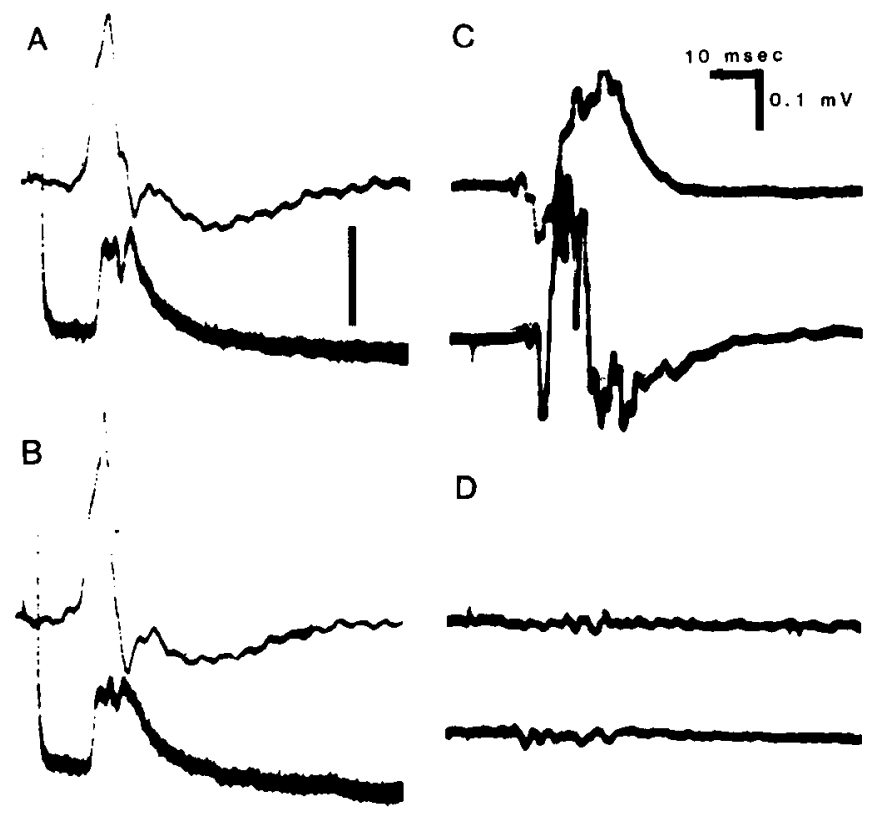

Figure 7. Extracellular recordings of St 43 iris (top trace) and ciliary body (bottom trace) electrical activity following single-shock ciliary nerve stimulation. Control electrical activity $(A)$ is not affected after $1 \mu \mathrm{M}$ atropine application $(B)$. In another preparation $(C), 1 \mu \mathrm{g} / \mathrm{ml} \alpha \mathrm{BTX}$ blocks almost all of the electrical activity recorded in both muscles $(D)$.

In Figure 7, $C$ (control) and $D$ (after $\alpha \mathrm{BTX}$ ), recordings similar to those shown in Figure 7, $A$ and $B$, demonstrate that $\alpha \mathrm{BTX}$ blocked most of the nerve-evoked compound action potential, even though a contracture remained in the iris and must therefore have been mediated by muscarinic receptors. The small electrical signals that persisted (Fig. $7 D$ ) were probably axon action potentials (See Pilar et al., 1981). In this case, a muscle contraction is maintained without extracellularly recordable electrical activity. This would be expected if the response were mediated by local depolarizations and mediated by muscarinic AChRs, rather than by junctional nicotinic receptors (due to $\alpha$ BTX blockade). Slow junctional potentials would not be detected with the extracellular recording technique used.

These experimental recordings provide indirect evidence that, at later stages, local depolarizations similar to those obscrved in slow tonic muscle fibers, as well as junctionally generated action potentials, can activate the iris muscle fibers, as has been described previously (Pilar and Vaughan, 1969b). At St 36, we attempted to record extracellular electrical responses in the iris and ciliary body muscles following stimulation of the ciliary nerves. The electrical response recorded was unchanged in both muscles after the addition of $10 \mu \mathrm{M}$ atropine and $7.5 \mu \mathrm{g} / \mathrm{ml}$ $\alpha$ BTX (not shown). Atropine alone blocked the visually observed contraction in both muscles, but $\alpha$ BTX had no effect on the mechanical response. These results imply that the electrical responses recorded in both muscles at this stage are due to action potentials in the nerves innervating them. Therefore, the muscular component in both the iris and the ciliary body at St 36 is either too small and sparsely distributed to be detected with extracellular recording, and/or both muscles are initially activatcd by muscarinic receptors, resulting in slow potentials not detectable by this recording technique.

Therefore, at St 34-36, both the iris and ciliary body muscle cells are probably synaptically activated by muscarinic $\mathrm{ACh}$

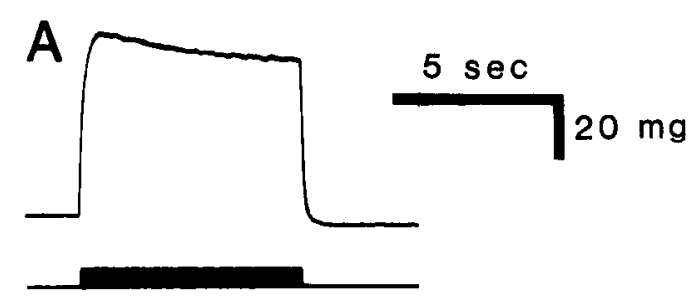

B

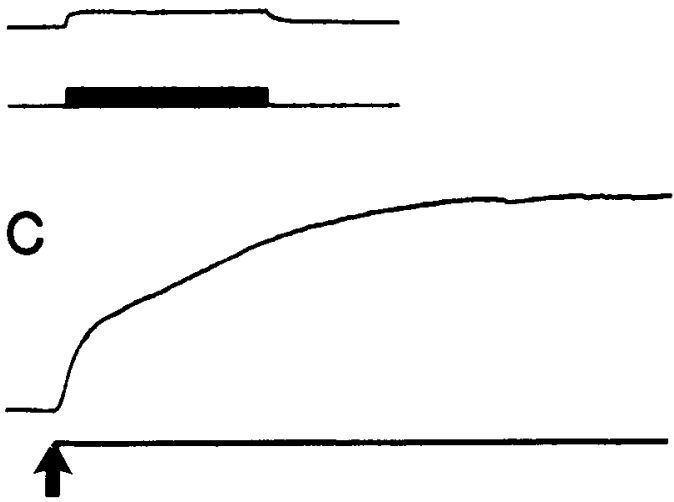

Figure 8. Effects of $\alpha \mathrm{BTX}$ and $\mathrm{ACh}$ application on iris muscle contractions in the adult bird ( $>6$ months old). $A$, Control tetanic contraction $(50 \mathrm{~Hz}) . B$, The tetanic contraction is almost completely blocked $35 \mathrm{~min}$ after $1 \mu \mathrm{g} / \mathrm{ml} \alpha \mathrm{BTX}$ is added to the perfusing solution. $C$, Iris contraction of the $\alpha \mathrm{BTX}$-poisoned iris is as strong as the control tetanic contraction after superfusion of ACh $(15 \mu \mathrm{M})$ and prostigmine $(1 \mu \mathrm{M})$, beginning at the arrow and continuing throughout the recording.

receptors. Later, the mechanical responses in the iris become fast (similar to the response seen in skeletal twitch muscle) and are mediated by nicotinic receptors. The changeover occurs between St 37 and hatching (see Fig. 5). Although it has not been determined which types of cholinergic receptors might be present in the muscle precursor cells before migration, our observations support the idea that, immediately after migration, the myoepithelial cells have muscarinic receptors, and that the first nerve-evoked response is mediated via these receptors. (At St 36, ACh and tetanic stimulation of the iris account for only about $50 \%$ of the $100 \mathrm{~mm} \mathrm{~K}^{+}$-induced contracturc. The appearance of $\mathrm{AChRs}$ on these muscle cells may occur after migration to the iris anlage.)

\section{Presence of nicotinic and muscarinic receptors in the same adult muscle fibers}

It is possible that during development there are always 2 populations of fibers present, and that, with time, the slow activation mediated by slow muscle fibers is masked by the much larger number of nicotinically activated fibers. A small population of slow fibers might be difficult to detect with the electron microscope. However, another possibility is that most of the nicotinic fibers in mature birds are also activated by muscarinic receptor stimulation, and that both receptor types are present in the same muscle cells. The observations described below support the latter hypothesis.

When development is complete, the nerve-evoked activation of the iris is purely nicotinic, and the number of myoepithelial cells, if they are present at all, is very small (see below). However, after almost all nerve-evoked muscular activity is blocked by 


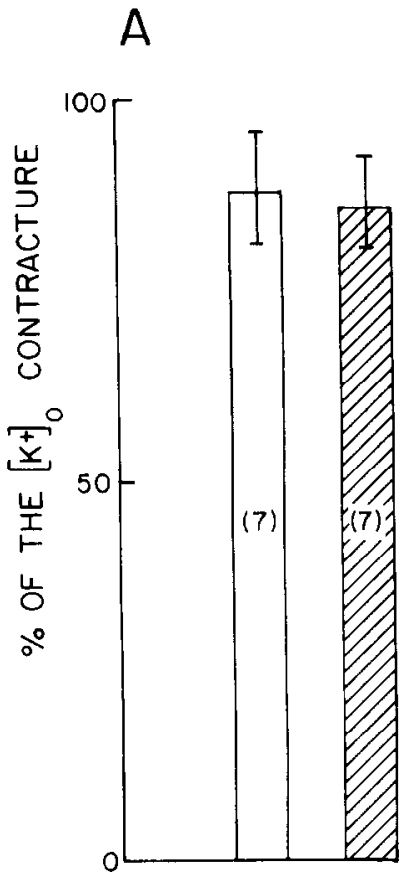

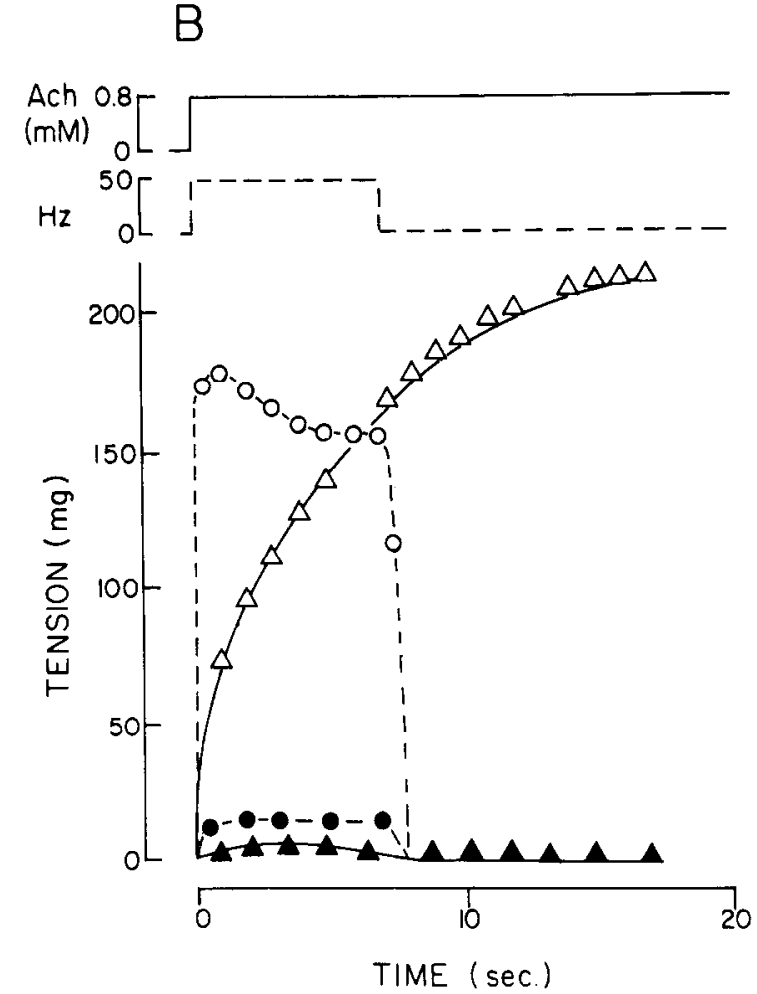

Figure 9. $A$, Iris contraction elicited by ACh application or repetitive nerve stimulation $(75 \mathrm{~Hz})$ is expressed as a percentage of the maximal iris contraction induced by $100 \mathrm{~mm} \mathrm{~K} \mathrm{~K}^{+}$. The open column represents the percentage of iris contraction when ACh $(0.5 \mathrm{mM})$ was added to the bath. The contraction obtained in this way is as large as the maximal $\mathrm{K}^{+}$contracture, indicating that $\mathrm{ACh}$ is activating all the muscle fibers. The percentage of contraction produced by nerve stimulation (striped col$u m n$ ) indicates that all the fibers are innervated. Numbers in parentheses are the number of samples. $B$, Effects of $\alpha$ BTX on iris neuromuscular transmission, and of atropine on the ACh-induced iris contracture are shown. The open circles represent the control tension during stimulation of the ciliary nerve. After addition of $\alpha \mathrm{BTX}(1 \mu \mathrm{g} /$ $\mathrm{ml}$ ), the nerve-induced response is almost eliminated (filled circles). Perfusion with ACh (0.5 mM) after $\alpha$ BTX treatment produces a strong iris contraction (open triangles). The ACh-induced contraction after atropine application $(0.2 \mathrm{~mm})$ to the $\alpha \mathrm{BTX}$-poisoned preparation is negligible filled triangles). $\alpha$ BTX [Figs. $8 B, 9 B$, open (control) and filled circles (after added $\alpha \mathrm{BTX})$ ], superfusion of the preparation with $\mathrm{ACh}$ or carbachol produced a contracture, or iris closure, of a size similar to that of the fused tetanic response after nerve stimulation (Figs. $8 C$, $9 B$, open triangles). This contracture was almost completely blocked by atropine (Fig. $9 B$, filled triangles). In addition, this ACh response (Fig. 9A, open bar) is similar in magnitude to that evoked by $100 \mathrm{~mm} \mathrm{~K}^{+}$, used as a control for the activation of all muscle fibers (Fig. 9A). The striped bar in Figure $9 A$ indicates that the tetanic response elicited by nerve stimulation is equal to the ACh-activated response.

These observations indicate that even striated muscle activation is not restricted to nicotinic receptors, and suggests that the same muscle fiber population can be stimulated by both muscarinic and nicotinic modes of activation. Further, since most of the iris fibers are activated by ACh superfusion following atropine blockade, it is clear that a large proportion of fibers with muscarinic receptors remain in the iris and can be activated at these older ages.

The most compelling evidence for the existence of both nicotinic and muscarinic receptors on the same muscle fiber was obtained by recording intracellularly from single muscle fibers in the hatched iris (see Fig. 10). Changes in membrane potential and resistance in the iris muscle fibers were monitored during continuous intracellular recording after the application of ACh ( $2 \mu 1,0.007 \mathrm{M}$; Fig. 10, arrows) near the recording electrode. The membrane resistance was determined by injecting short depolarizing pulses through the recording pipette at $50 \mathrm{msec}$ intervals (inset, Fig. 10A). In the cell illustrated in Figure $10 \mathrm{~A}$, a rapid depolarization occurred, with a concomitant increase in membrane conductance (recorded as a decrease in resistance; second trace of inset), followed by a short period of repolarization and a subsequent longer-lasting depolarization. This late depolarization was accompanied by a conductance decrease (see third trace of inset, Fig. 10A). This behavior was observed in 10 cells impaled at random. The late depolarization could be maintained for up to $100 \mathrm{sec}$, but the accompanying contracture, localized around the recording microelectrode, made it difficult to maintain the penetration in the cells for the duration of the response. The initial depolarization and conductance increase could be blocked by $\alpha$ BTX ( $1 \mu \mathrm{g} / \mathrm{ml}$; Fig. 10B), leaving the slower depolarization with a concomitant conductance decrease. Therefore, the initial response to $\mathrm{ACh}$ by the hatched iris muscle fiber is mediated via nicotinic receptors and appears to be analogous to muscle endplate nicotinic receptors, which cause an increase in membrane conductance (Anderson and Stevens, 1973). The slow-onset, $\alpha \mathrm{BTX}$-insensitive depolarization is most likely due to the activation of muscarinic receptors on these fibers, which in turn may close a $\mathrm{K}^{+}$conductance (Sims et al., 1985).

\section{Localization of receptors in synaptic and extrasynaptic muscle regions}

From the analysis of the mechanical records obtained after nerve stimulation and $\mathrm{ACh}$ superfusion in the presence of cholinergic blockers, we propose that since the response to nerve stimulation in the mature iris fibers is abolished by $\alpha \mathrm{BTX}$, it is mediated by nicotinic receptors, and that the responses mediated by muscarinic receptors after $\mathrm{ACh}$ superfusion are largely extrasynaptic. Since a similar tension was obtained with ACh superfusion after the differential block with either nicotinic or muscarinic ligands, at least many of the same muscle fibers must possess both types of receptors (confirmed by intracellular recordings; see preceding paragraph). However, it is clear from Figures $5 C, 8 B$, and $9 B$ (circles) that some muscarinic receptors are synaptically activated.

Figure $8 B$ demonstrates the ability of $\alpha \mathrm{BTX}$ to substantially block the tetanic contraction in the adult ( $>6$ months) iris. Despite this nicotinic blockade, the preparation contraction was 


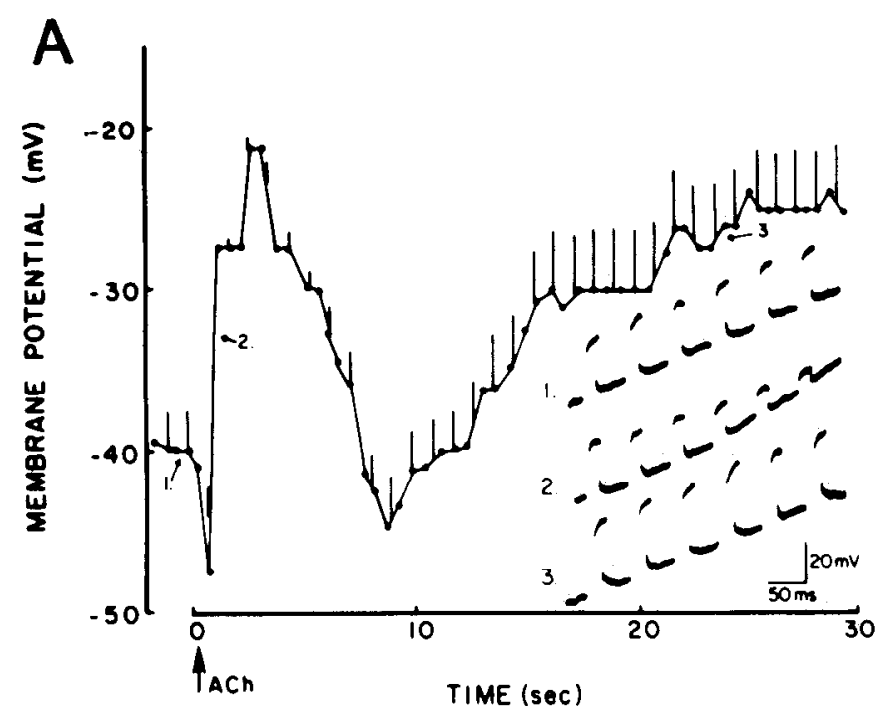

B

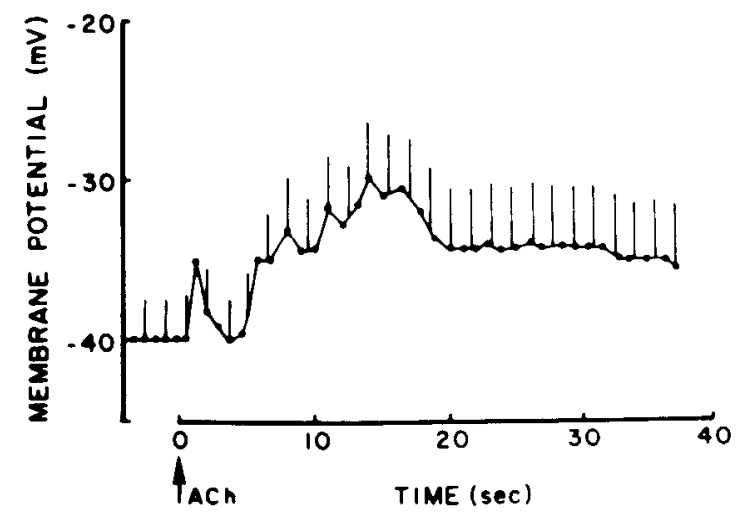

Figure 10. Time course of iris membrane potential and conductance changes (illustrated as depolarizing pulses and shown in the inset) elicited by a microinjection of $\mathrm{ACh}(2 \mu \mathrm{l}, 0.007 \mathrm{M}) . A$, Control response of an iris muscle fiber, with selected conductance changes shown in the inset. In this experiment the electrode was withdrawn after $30 \mathrm{sec}$ to ascertain the membrane potential value. $B$, In another cell, the response $1 \mathrm{hr}$ after $\alpha$ BTX $(1 \mu \mathrm{g} / \mathrm{ml})$ treatment. Both graphs are drawings of the potential changes recorded on film; samples of the film records are illustrated in the inset. The numbers preceding the film traces correspond to the numbered arrows in the graph.

as strong as the control tetanic response after $\mathrm{ACh}$ application (Fig. $8 C$ ), this response being blocked by atropine. The possibility that this response is mediated by extrasynaptic muscarinic receptors was further investigated. Blocking $\mathrm{AChE}$ (by prostigmine) should allow $\mathrm{ACh}$ to diffuse further from the synapse, activating more distant "extrasynaptic" receptors. If these receptors are not activated by nerve stimulation because they are too distant from the synapse (the focal point of release), it might be possible to stimulate them by preventing the hydrolysis of the released $\mathrm{ACh}$. The results of this experiment arc illustratcd in Figure 11.

The control tetanic response recorded in a $3 \mathrm{dph}$ chick (Fig. $11 \mathrm{~A}$ ) was completely blocked by a $1 \mathrm{hr}$ exposure to $3.7 \mu \mathrm{g} / \mathrm{ml}$

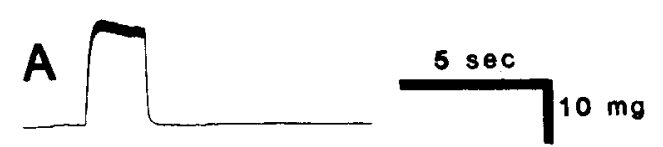

B

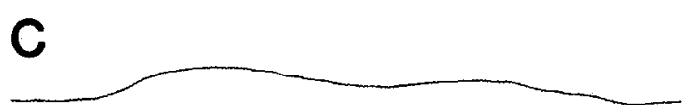

D

Figure 11. Effects of prostigmine of the $\alpha \mathrm{BTX}$-poisoned tetanic response of a $3 \mathrm{dph}$ iris. $A$, Control tetanus after $40 \mathrm{~Hz}$ nerve stimulation. $B$, The tetanic contraction is completely blocked $1 \mathrm{hr}$ after $\alpha \mathrm{BTX}(3.7$ $\mu \mathrm{g} / \mathrm{ml})$ superfusion. $C$, Thirty minutes of prostigmine $(106 \mathrm{gm} / \mathrm{ml})$ allow the recording of a slow-onset, long-lasting contraction that is blocked by $1 \mu \mathrm{M}$ atropine $(D)$.

$\alpha$ BTX (Fig. 11B). Prostigmine treatment of the $\alpha$ BTX-poisoned preparation resulted in the appearance of a slow-onset prolonged contraction in response to $40 \mathrm{~Hz}$ nerve stimulation (Fig. 11C), and this contraction was completely blocked by $1 \mu \mathrm{M}$ atropine (Fig. 1D). This slow atropine-sensitive contraction is reminiscent of the St 36 iris mechanical response. The main difference between a $\mathrm{St} 36$ iris and a posthatch iris is that few, if any, myoepithelial cells remain in the iris after hatching. The muscarinic response to $\mathrm{ACh}$ must therefore be occurring in the striated muscle fibers. The results of these experiments support the hypothesis of extrasynaptic localization of muscarinic receptors in striated fibers of the iris, but do not exclude the likelihood of their subsynaptic localization.

\section{Cholinergic receptor characterization by radioligand receptor binding}

$\alpha \mathrm{BTX}$ and QNB are well-established markers for peripheral cholinergic receptors, particularly since they show no mutual competition in binding assays. ${ }^{3} \mathrm{H}-\mathrm{QNB}$ binds with high specificity to a single, high-affinity saturable site (Yamamura and Snyder, 1974). The analysis of ${ }^{3} \mathrm{H}-\mathrm{QNB}$ binding was done on homogenates of pigment-cleaned irises from albino chickens in order to avoid interference by low-affinity, but high-capacity, binding to the pigmented epithelium. These homogenates contained a small number of binding sites that were saturable with ${ }^{3} \mathrm{H}-\mathrm{QNB}$. The nonspecific binding varied with the age of the chicken; it was less than $10 \%$ of the total binding in irises from embryonic chickens, but reached $30 \%$ in adult irises.

Table 1 displays the values of ${ }^{3} \mathrm{H}-\mathrm{QNB}$ binding at different embryonic ages. Low levels of binding were found at St 37 (less than $0.5 \mathrm{fmol})$. Thereafter, there was an increase in ${ }^{3} \mathrm{H}-\mathrm{QNB}$ binding, a reflection, in part, of the increased mass of the iris. However, there was a large decrease in binding/mg protein after hatching.

Nicotinic binding sites have previously been measured with ${ }^{125}$ I- $\alpha$ BTX (Chiappinelli and Giacobini, 1978). At the earliest 

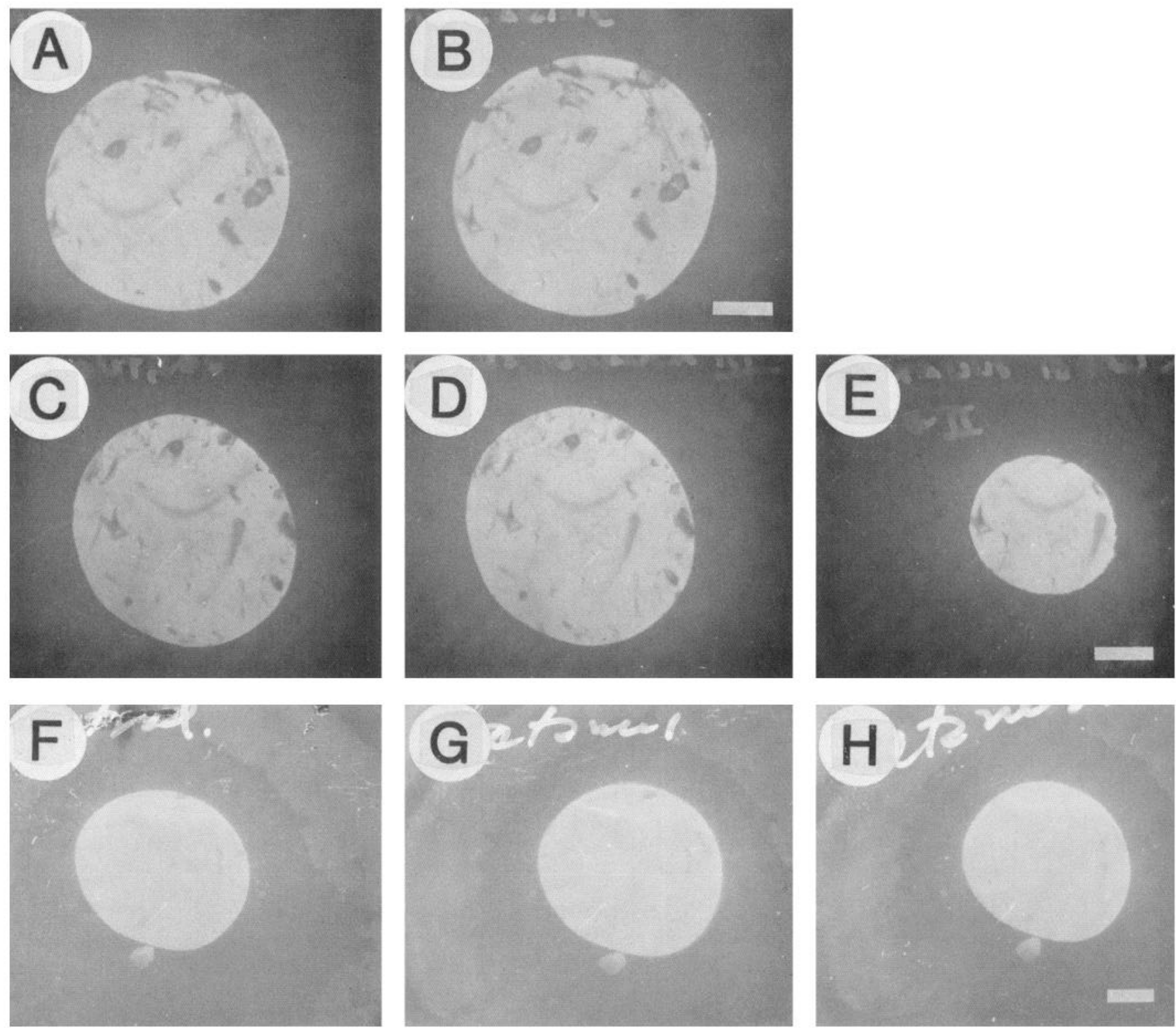

Figure 12. Pupillomorphic photographs demonstrating the dilator response. $A$, Control iris (6 months old). $B$, Iris dilation in response to $10 \mathrm{~nm}$ muscarine application. $C$, Control iris (6 months old). $D$, Iris dilation in response to stimulation $(50 \mathrm{~Hz})$ of ciliary nerve branch III. $E$, Iris constriction in response to stimulation $(50 \mathrm{~Hz})$ of ciliary nerve branches I and II $(50 \mathrm{~Hz}) . F$, Control iris $(18 \mathrm{dph})$. $G$, Iris dilation in response to ciliary nerve branch III stimulation $(50 \mathrm{~Hz}) . H$, Blockade of the dilation observed in $(G)$ by the addition of $1 \mu \mathrm{g} / \mathrm{ml} \alpha \mathrm{BTX}$ to the perfusion solution 40 min before branch III stimulation. All calibrations, $1 \mathrm{~mm}$.

stages of neuromuscular transmission in the chick iris (St 3436), less than $1 \mathrm{fmol} \alpha \mathrm{BTX}$ per iris was detected (this is consistent with our observation that the mechanical response of the iris to nerve stimulation is insensitive to $\alpha \mathrm{BTX}$ ). By St 38 , a small amount of specific ${ }^{125} \mathrm{I}-\alpha \mathrm{BTX}$ binding was reported, and this binding increased progressively as neuromuscular transmission attained adult characteristics (Pilar et al., 1981).

The pharmacological evidence is consistent with the presence of specific binding of ${ }^{3} \mathrm{H}-\mathrm{QNB}$ and ${ }^{125} \mathrm{I}-\alpha \mathrm{BTX}$ in the developing and mature control iris. Although a causal correlation exists between nicotinic $\mathrm{AChR}$ development and neural innervation, it is not known whether this innervation directly influences $\mathrm{AChR}$ development in the iris.

\section{Dilator muscle}

The dilator fibers cannot be activated separately from the constrictor fibers with the method of stimulation used in this paper, and the large response of the constrictor masks most of the response of the weak dilator muscle. It is only after blocking the nicotinic response in the posthatch iris with $\alpha \mathrm{BTX}$ that these dilator responses are often seen. Pupillomorphic measurements in the adult following superfusion of the agonist muscarine (Fig. $12 B$ ) demonstrate a pupillary enlargement compared to control (Fig. 12A). Since in older birds, muscarine (10 nM) would be expected to activate both dilator and constrictor muscles, the fact that overall dilation occurred under these conditions would 


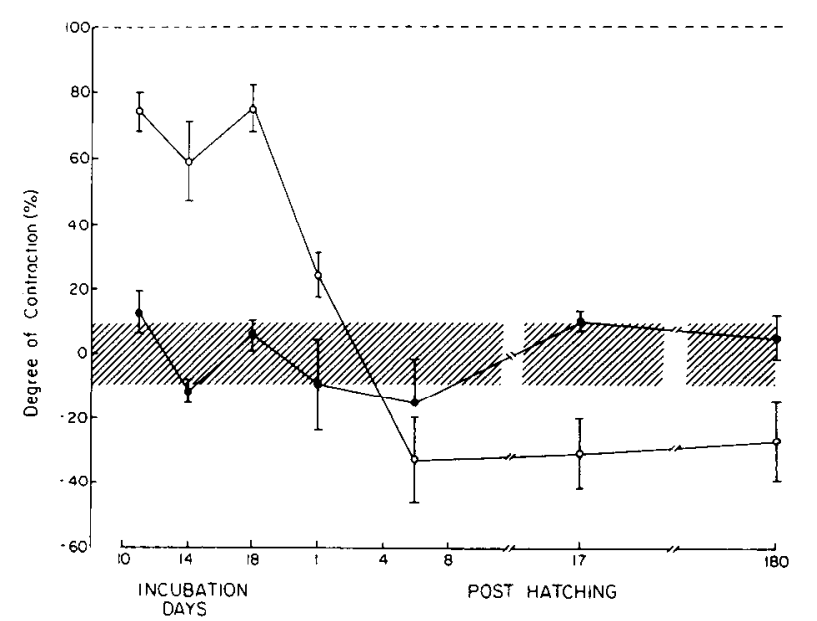

Figure 13. Developmental time course of the dilator response of the iris obtained by pupillomorphic analysis after tetanic ciliary nerve stimulation. Control tetanic contractions at each age are defined as $100 \%$ contraction and indicated by a dotted line. $\alpha \mathrm{BTX}, 1 \mu \mathrm{g} / \mathrm{ml}$, (open circles) decreases the contractile response such that after hatching a pupillary dilation is apparent. $\alpha \mathrm{BTX}(1 \mu \mathrm{g} / \mathrm{ml})+$ atropine $(1 \mu \mathrm{M})$ completely eliminates all pupillary responses (circles). The stippled bar is 0 contraction. Mean \pm SE.

suggest that the dilator has a stronger muscarinic component than does the constrictor. Before St 39, muscarine application did not result in dilation of the iris pupil. The dilator fibers may not be organizcd at this stage (Gabclla and Clarkc, 1983). However, the developmental time course of this nerve-evoked dilation is shown in Figure 13. A dilator response was elicited by this method from $\mathrm{St} 42$ to 11/2 years of age.

Iris dilation can also be caused by the selective stimulation of a small nerve emanating from branch III that contains axons projecting to the dilator muscle (Pilar et al., 1980) (Fig. 12C, control). Single pulses did not elicit a response, and dilation became evident only after repetitive nerve stimulation (Fig. $12 D$ ). Figure $12 E$ is the constrictor response observed following stimulation of branches II and III. The dilator response had a longer time course than that of the constrictor response and was still present after the termination of the stimulation pulse. With this procedure, it was possible to test whether the dilator fibers also have nicotinic receptors. Figure $12, F-H$, shows that $\alpha \mathrm{BTX}$ application (Fig. $12 H$ ) can prevent the dilation (Fig. 12G), indicating that, in addition to their abundance of muscarinic receptors (evident after muscarine application), dilator fibers also

Table 1. Specific ${ }^{3} \mathrm{H}-\mathrm{QNB}\left(10^{-15} \mathrm{~mol}\right)$ binding (mean $\left.\pm \mathrm{SE}\right)$ in chick iris during development

\begin{tabular}{rlcl}
$\begin{array}{l}\text { Age } \\
\text { (d) }\end{array}$ & St & fmol/iris & fmol/mg protein \\
\hline 11 & 37 & $0.45 \pm 0.04$ & $37.5 \pm 4 \quad(4)$ \\
17 & 41 & 1.41 & $54.3^{a}$ \\
1 & Posthatch & $2.11 \pm 0.34$ & $72.8 \pm 8.8 \quad(5)$ \\
14 & & $3.89 \pm 0.48$ & $62.1 \pm 14.5(5)$ \\
180 & & $31.12 \pm 4.21$ & $27.9 \pm 8.2 \quad(6)$
\end{tabular}

$\overline{\text { Determinations were made in albino chickens to avoid binding to pigment. As }}$ an example, the following values are given for comparison: albino $1 \mathrm{~d}$ posthatch $=$ $2.11 \mathrm{vs}$ pigmented $1 \mathrm{~d}$ posthatch $=113.5 \mathrm{fmol} /$ iris.

a Obtained from Scatchard plot using a pool of 69 irises. The number of experiments is given in parentheses.
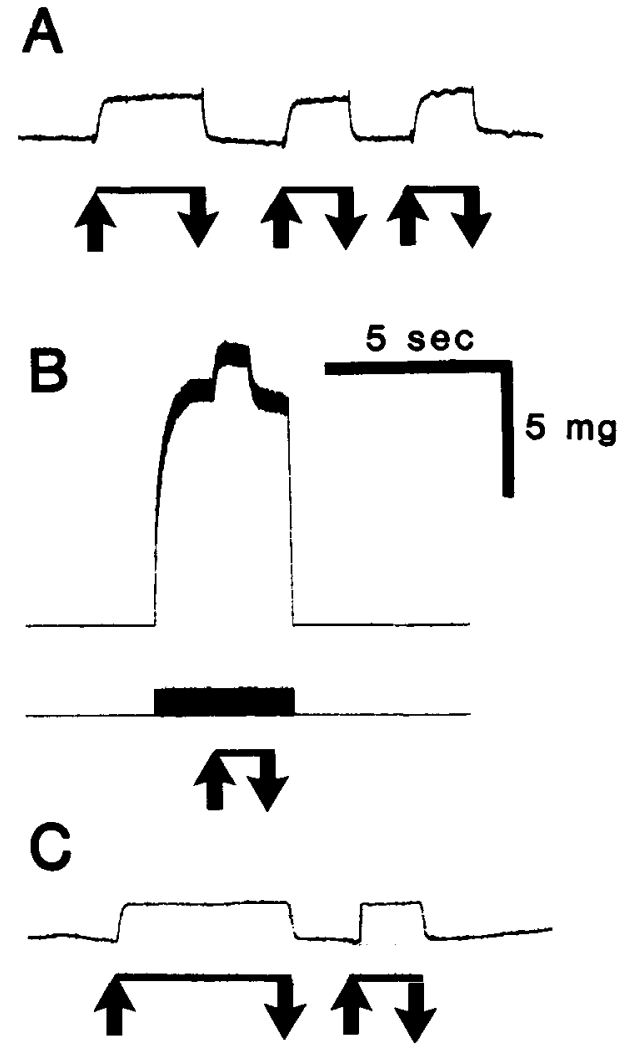

Figure 14. Light-activated contraction in the iris ( $9 \mathrm{dph}) . A$, Contractions of the iris in response to turning on (arrow pointing up) and turning off (arrow pointing down) a bright tungsten lamp. $B$, Light-activated contraction superimposed on a tetanic contraction $(50 \mathrm{~Hz}) . C$, The light response persists in the denervated iris.

have nicotinic receptors at junctional sites. Figure $12 F$ is the control iris.

There has been a report suggesting the existence of adrenergic innervation of the dilator muscle, based on catecholamine fluorescence (Kirby et al., 1978). In a few experiments we attempted to determine whether norepinephrine or epinephrine could modify the iris aperture. Using the experimental approaches described above, we did not detect any effect of these agents. However, they may be involved in a subtle modulatory role, interacting, perhaps, with the cholinergic innervation we have described.

\section{Light-activated contraction}

In addition to nervous control, there is a direct constrictory effect of light on the iris. During the course of experimentation, especially at embryonic stages, it was found that sudden changes of illumination modified the iris aperture. Similar responses were also obtained during muscle tension recordings. Figure $14 \mathrm{~A}$ demonstrates that turning on a bright tungsten lamp evokes a fast contracture in the iris, which subsides when the light is turned off. The response can also be superimposed on a prolonged nerve-evoked tetanic response (Fig. 14B) or on an AChinduced contraction (not shown). The light response is also elicited in the absence of $\mathrm{Ca}^{2+}$ (not shown) after neuromuscular junction blockade with both nicotinic and muscarinic blockers (not shown) and in the denervated iris (Fig. 14C) (see Pilar and Landmesser, 1972, for details of the denervation procedure).

The light response seen at earlier stages represents a large 


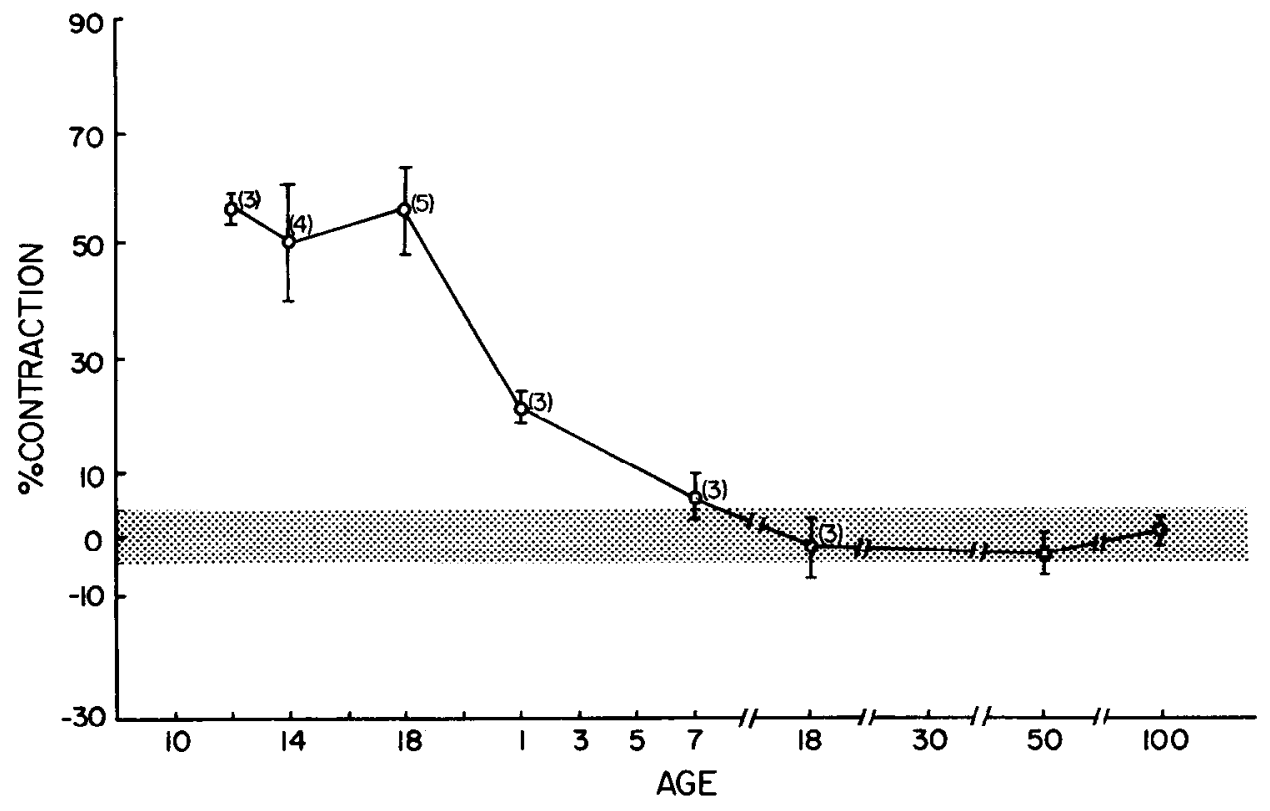

Figure 15. Developmental time course of the light response obtained from strain-gauge measurements of tension in the isolated iris. At early embryonic ages, the light response can produce an iris constriction that is $60 \%$ of the tetanic response of the iris. After $18 \mathrm{dph}$, the iris's contractile response to light is negligible compared to the control tetanic response. The stippled bar is 0 contraction. percentage of the total iris contraction (up to 60\% at St 36-44). At later stages the response is less, and becomes insignificant by about $18 \mathrm{dph}$ (see Fig. 15).

The light source used in these observations was a regular microscope illumination lamp. No attempts were made to determine the light sensitivity spectrum of the chick iris response, but it was noted that red light did not evoke a contractile response.

\section{Characterization of the contractile elements in the iris}

Because the chick iris demonstrates 2 distinct types of pharmacological and contractile properties during development, it is possible that 2 distinct muscle fiber types are present in the iris during embryogenesis. In fact, 2 different types of contractile elements were seen ultrastructurally during embryogenesis: myoepithelial cells and striated muscle cells. This is reminiscent of the smooth and striated muscle fiber composition observed in the alligator iris (Reger, 1966).

For identification of the contractile elements, we compared the cellular elements in the iris at the 2 developmental periods, St 35-37 (Fig. 16A) and posthatch (Fig. 16B), characterized by distinct physiological responses to nerve stimulation. As described earlier, at about St 35-37 there was a slow, protracted response to repetitive stimulation and no twitch response. The predominant elements observed in the electron microscope at this stage were long branched cells (5-8 $\mu \mathrm{m}, 1-3 \mu \mathrm{m}$ diameter) surrounded by a basal lamina (see Fig. 16A). The major constituent of these cells was a dense cytoplasm packed with filaments. At irregular intervals, the cell membrane displayed conspicuous longitudinally oriented dense "patch zones," and these cells had large nuclei occupying a somewhat central position, with chromatin appearing in the periphery of the nucleus. All of these characteristics are similar to those seen in myoepithelial cells (Young and Van Lennep, 1977; Redman et al., 1980), and we assume that these cells are the contractile elements responsible for the "smooth" muscle response seen in the iris at early embryonic ages. Early irises also had bundles of unmyelinated axons, which on occasion were seen abutting the myoepithelial cells, exhibiting many of the characteristics of a terminal ending (see Fig. 17). Descriptions of the earlier neuromuscular contacts have been already published (Lucchi et al., 1974; Pilar et al., 1980, 1981).

After hatching, "skeletal"-type muscle cells were clearly recognizable by the sarcomeric organization of their myofibrils (Fig. $16 B)$. These muscle fibers were also branched, thin $(1-3 \mu \mathrm{m})$, and elongated $(5-10 \mu \mathrm{m})$. The description of these muscle fibers will not be repeated here (see Pilar et al., 1981; Gabella and Clarke, 1983), but there is little doubt that these cells are responsible for the "skeletal" type of muscle contraction.

At developmental stages between the 2 described above, there were different proportions of these 2 clearly defined contractile cellular elements. At St 40, there was still a large proportion of myoepithelial cells (40\%), although they were not uniformly distributed in the iris, appearing more frequently near the pupillary edge than in the iris root (most samples in our investigations were taken from the central portion of the iris). The earliest point at which we observed filaments organized as sarcomeres was at St 37, which marks the initiation of the fast muscular response. After this stage, many cells showed different stages of sarcomeric organization. After St 38, fully organized myofibrils were seen, and the amount of endoplasmic reticulum was increased. A large number of mitochondria were seen, especially near the periphery of the striated muscle cells. A week after hatching, myoepithelial cells were not seen in large EM reconstructions of the iris.

A careful search was made for pigment granules in the contractile cells. In Figure 16A, granules (arrows) are clearly seen in the myoepithelial cells. These granules are seen less frequently in striated muscle fibers; however, there is no doubt that pigment granules (Fig. 16B, arrows) can be found in these striated cells. This finding provides only circumstantial evidence for the transformation of pigment-containing epithelial cells to myoepithelial cells, and subsequently to "striated" muscle cells (discussed below).

\section{Discussion}

The main findings of this work are that the initial synaptic activation of the iris (St 34-36) is mediated via muscarinic 

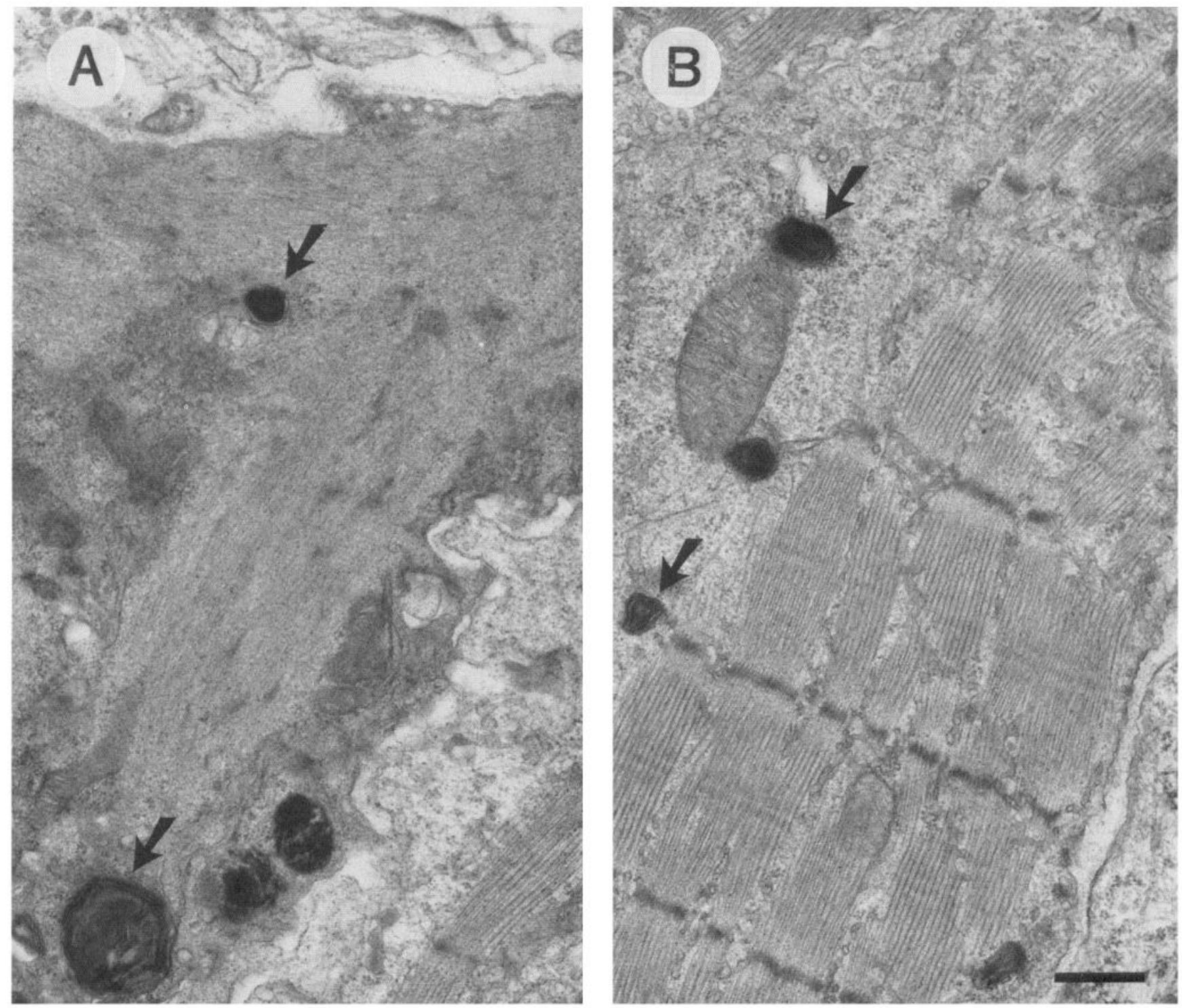

Figure 16. Electron micrographs taken from a St 44 iris demonstrate both myoepithelial and striated contractile elements. $A$, Myoepithelial cell with densely packed cytoplasmic filaments. Lamellar pigment granules, which may mediate the light-induced contractions, are indicated by arrows. $B$, Striated muscle cell with contractile filaments organized into sarcomeres. Lamellar pigment granules, which may mediate the light-induced contractions, are indicated by arrows. Calibration, $0.5 \mu \mathrm{m}$.

receptors on myoepithelial cells (this coincides with the beginning of the neuronal competition for survival; see Landmesser and Pilar, 1974). Halfway through this normal neuronal death period, nicotinic activation begins on newly formed striated muscle fibers. However, these striated fibers also have muscarinic receptors, which are probably extrasynaptic and not appropriately positioned relative to nicotinic receptors to be signifcantly activated by nerve-released $\mathrm{ACh}$. There are close contacts between nerve terminals and muscle in both the striated and the smooth fibers that may represent neuromuscular junctions, since the axon terminals have accumulations of synaptic organelles (see Pilar et al., 1981, for an extensive description). The striated fibers of the dilator muscle also have both types of receptors, but the appearance of this muscle as a functional unit (at about St 39, almost the end of the natural neuronal death period) is later than the development of the constrictor. Functionally, myoepithelial cell synaptic activation is via muscarinic receptors, and striated muscle cell activation is via nicotinic receptors.

In addition, we report that the mature striated iris muscle fibers have both nicotinic and muscarinic receptors on the same muscle cells (the nicotinic being primarily synaptic, and the muscarinic predominantly extrasynaptic). The ciliary body muscle fibers also appear to be initially activated by muscarinic receptors, but we have not investigated the development of ciliary body cholinergic pharmacology as extensively as that of the iris. A similar developmental sequence in the ciliary body would not be surprising, considering the probability of a similar embryological origin for both muscles (see below). Classically, skeletal muscle is considered to be entirely nicotinic, and smooth and heart muscle muscarinic.

Myoepithelial cells are present in mammalian exocrine glands (Young and Van Lennep, 1977), including mammary, lacrimal, salivary, and sweat glands. The cells are termed myoepithelial 


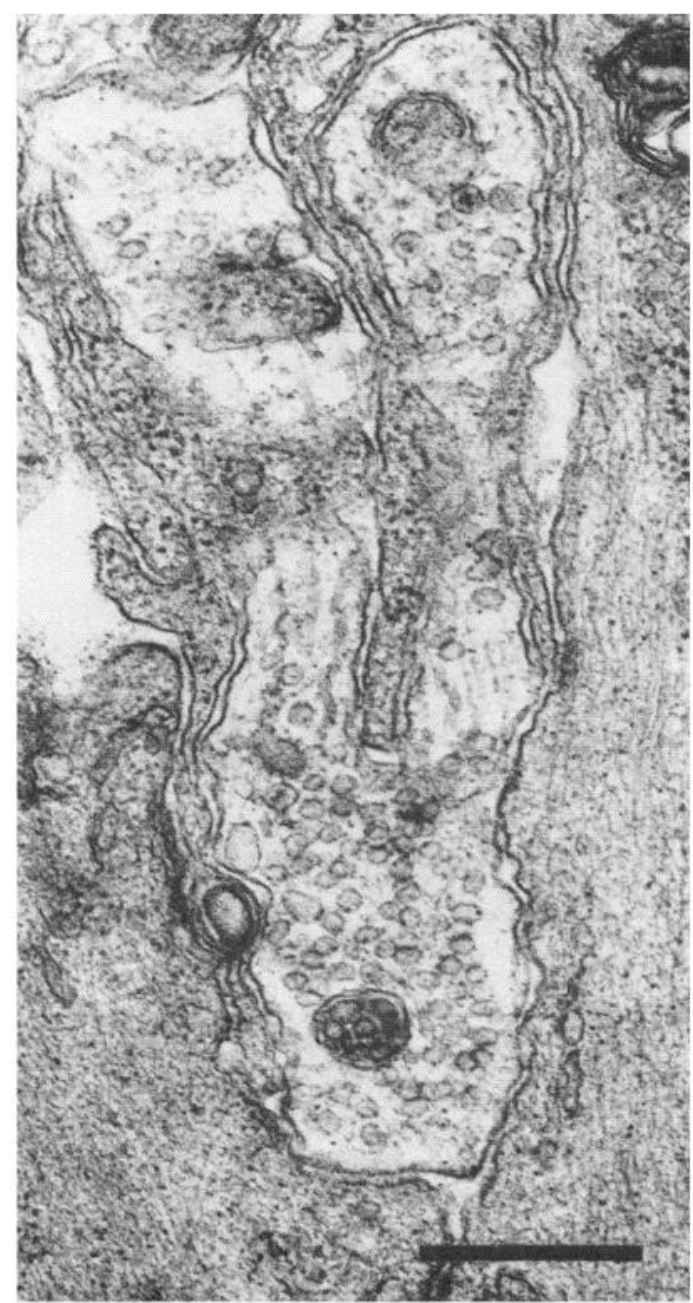

Figure 17. Electron micrograph taken from a St 42 iris demonstrates a vesicle-filled nerve process abutting a myoepithelial cell. Calibration, $0.5 \mu \mathrm{m}$.

because they have features of both epithelium and smooth muscle and are embryologically derived from epithelium. The myoepithelial cell responses we observed in the iris are similar to those observed elsewhere in innervated quiescent smooth fibers (Creed, 1979), with a long initiation latency and a prolonged relaxation time course (Bolton, 1979).

Another functional characteristic of the developing iris is a mechanical response elicited by light, which gradually disappears after hatching. This light response of the chick iris is, in many respects, similar to the response that occurs in amphibians. In fish and amphibians, the smooth muscle of the iris responds to light with a contraction (Seliger, 1962; Barr and Alpern, 1963) due to an increase in intracellular $\mathrm{Ca}^{2+}$ (Kargarin and Detwiler, 1985). The similarities of the response obtained in the chick iris to that previously described in the frog suggest a similar mechanism for muscle activation: the release of $\mathrm{Ca}^{2+}$ from intracellular stores by a still unknown phototransduction process. Pigment granules (containing rhodopsin or some other photosensitive pigment) could be the source of this $\mathrm{Ca}^{2+}$ release in the chick. The decreasing contractile response to light with age is also in accord with the decreased number of myoepithelium cells in older irises, and with the many fewer pigment granules in the skeletal fibers.
The presence of 2 types of cholinergic receptors in excitable cells is not a novel finding. Parasympathetic ganglion cells respond to ACh with a fast postsynaptic potential mediated by nicotinic receptors, and a slow postsynaptic potential mediated by muscarinic receptors (Nishi, 1974). Multiple receptors have also been shown in Aplysia cell bodies and in smooth muscle cells (Gardner and Kandel, 1977; Bolton, 1979). In the chick iris, the muscarinic receptors appear first, but we could not determine whether or not the muscarinic receptors were present before the innervation was established. A temporal correlation between the appearance of nicotinic subsynaptic receptors and the formation of neuromuscular junctions has been observed, and this coincides with the first appearance of muscles with sarcomeric organization.

However, an interesting feature of this study is the sequence of cholinergic receptor appearance in the iris. Initially, muscarinic receptors are present in the myoepithelial cells. Later, nicotinic receptors are present in the striated fibers, but these fibers either retain the muscarinic receptors of myoepithelial precursors or express them simultaneously as they develop junctional nicotinic characteristics after migrating from the neural crest (Nakano and Nakamura, 1985). These 2 possibilities depend on the embryological origin of the contractile cells in the iris, which is somewhat controversial. Do the myoepithelial cells and the striated muscle cells arise from separate precursor populations, or are the myoepithelial cells a transitory stage in the formation of striated muscle fibers?

Gabella and Clarke (1983) proposed that the smooth muscle fibers (myoepithelial cells in our study), which are confined to the iris pupillary region, are derived from the ectoderm (of retinal origin), while the striated musculature originates from undifferentiated cells of the iris anlage, regarded as mesenchymal. These researchers also confirmed that the smooth muscle cells are derived from the posterior pigment epithelium, as was suggested earlier (Lewis, 1903). This is not surprising, since many of these smooth muscle cells contain pigment granules, as do smooth muscle fibers of the frog and alligator (Reger, 1966).

The mesenchymal origin of striated cells was recently given support by investigations using the chick-quail chimeras developed by Le Douarin (1973). Nakano and Nakamura (1985) showed that the striated dilator and constrictor muscles are of neural crest origin, as is the ciliary muscle (Johnston et al., 1979). The cells migrating from the neural crest (in the dorsal part of the embryonic diencephalon) form the mesenchyme of the iris (Nakano and Nakamura, 1985), from which the striated muscle cells are apparently derived. Moreover, these workers concluded that the irideal epithelium cells were not of neural crest origin, although they did not speculate on the origin of the myoepithelial cells.

A neural crest origin of the striated fibers in the iris may explain the presence of both muscarinic and nicotinic $\mathrm{ACh}$ receptors in the same muscle fibers in the adult iris. The phenotypic differentiation of neural crest-derived cells has been shown to be plastic and heavily influenced by the environment and local interactions between cells (Le Douarin et al., 1981). Therefore, it would not be surprising if striated muscle derived from neural crest expressed more than one receptor phenotype during development. Skeletal striated muscle cells, which only express nicotinic ACh receptors, are not of neural crest origin, but arise from the somites or somatopleural mesenchyme.

However, as strong as is the possibility for an independent 
origin of smooth muscle and striated fibers, there are observations, such as of the appearance of pigment granules in striated muscle cells, that at least point to the possibility that the myoepithelial cells are a transitional cell type for at least some striated muscle cells (as was suggested originally by Brini et al., 1964). In short, the observations in this study are compatible both with hypotheses of independent origins for the iris smooth (myoepithelial, ectodermal) and striated (neural crest) muscles and with those suggesting a common origin for both (the neural crest).

The detailed presentation of this data is interesting for several reasons. First, the iris and ciliary body undergo a change in contractile behavior from a slow, smooth muscle response to a striated muscle response during embryogenesis. Second, there is the novel observation of the existence and development of 2 ACh receptor types (muscarinic and nicotinic) in the same muscle fibers of the adult iris. Finally, the characteristics of pharmacological activation of the embryonic iris described allow one to predict the actions of anticholinergic drugs on the target of the ciliary neuron population. This information is crucial for determining the role of peripheral activity in the regulation of naturally occurring neuronal death, which is explored in the third paper of this series (Meriney et al., 1987).

\section{References}

Anderson, C. R., and C. F. Stevens (1973) Voltage clamp analysis of acetylcholine produced endplate current fluctuations at the frog neuromuscular junction. J. Physiol. (Lond.) 235: 655-691.

Barr, L., and M. Alpern (1963) Photosensitivity of the frog iris. J. Gen. Physiol. 46: 1249-1265.

Bolton, T. B. (1979) Mechanisms of action of transmitters and other substances on smooth muscle. Physiol. Rev. 59:606-717.

Brini, A., A. Porte, and M. E. Stoeckel (1964) Developement ultrastructural des muscles iriens chez l'embryon de poulet. Soc. Fr. d'Opthalmol. Bull. Mem. 77: 488-497.

Chiappinelli, V. A., and E. Giacobini (1978) Time course of appearance of $\alpha$-bungarotoxin binding sites during development of chick ciliary ganglion and iris. Neurochem. Res. 3: 465-478.

Creed, K. E. (1979) Functional diversity of smooth muscle. Br. Med. Bull. 35:243-247.

Durand, G. (1893) Disposition et developement des muscles dans l'iris des oiseaux. J. Anat. Physiol. Norm. et Pathol. l'Homme Anim. 29: 604-636.

Ferrari, P. A., and W. E. Koch (1984a) Development of the iris in the chicken embryo. I. A study of growth and histodifferentiation utilizing immunocytochemistry for muscle differentiation. J. Embryol. Exp. Morphol. 81: 153-167.

Ferrari, P. A., and W. E. Koch (1984b) Development of the iris in the chicken embryo. II. Differentiation of the irideal muscle in vitro. J. Embryol. Exp. Morphol. 81: 169-183.

Gabella, G., and E. Clarke (1983) Embryonic development of the smooth and striated musculatures of the chicken iris. Cell Tissue Res. 229: 37-59.

Gardner, D., and E. R. Kandel (1977) Physiological and kinetic properties of cholinergic receptors activated by multiaction interneurons in buccal ganglia of Aplysia. J. Neurophysiol. 40: 333-348.

Geberg, A. (1884) Uber die nerven der iris und des ciliarkorpers bei vogeln. Int. Monatsschr. Anat. Histol. 1: 7-52.

Goodman, L. S., and A. Gilman (1975) The Pharmacological Basis of Therapeutics, pp. 433, Macmillan, New York.

Hamburger, V., and H. L. Hamilton (1951) A series of normal stages in the development of the chick embryo. J. Morphol. 88: 49-92.

Johnston, M. C., D. M. Noden, R. D. Hazelton, J. L. Coulombre, and A. J. Coulombre (1979) Origins of avian ocular and periocular tissues. Exp. Eye Res. 29: 27-43.

Kargarin, G. J., and P. B. Detwiler (1985) Light evoked contraction of the photosensitive iris of the frog. J. Neurosci. 5: 3081-3087.

Kirby, M. L., I. M. Diab, and T. G. Mattio (1978) Development of adrenergic innervation of the iris and fluorescent ganglion cells in the choroid of the chick eye. Anat. Rec. 191: 311-320.

Kloog, Y., D. S. Heron, A. D. Korcyzyn, D. I. Sachs, and M. Sokolovsky
(1979) Muscarinic acetylcholine receptors in albino rabbit iris-ciliary body. Mol. Pharmacol. 15: 581-589.

Landmesser, L., and G. Pilar (1974) Synaptic transmission and cell death during normal ganglionic development. J. Physiol. (Lond.) 241: 737-749.

Le Douarin, N. M. (1973) A biological cell labeling technique and its use in experimental embryology. Dev. Biol. 30: 217-222.

Le Douarin, N. M., J. Smith, and C. S. Le Lievre (1981) From the neural crest to the ganglion of the peripheral nervous system. Annu. Rev. Physiol. 43: 653-671.

Lewis, W. H. (1903) Wandering pigmented cells arising from the epithelium of the optic cup, with observations on the origin of the $\mathrm{m}$. sphincter pupillae in the chick. Am. J. Anat. 2: 405-416.

Lowry, O. H., N. J. Rosenbrough, A. L. Farr, and R. J. Randall (1951) Protein measurement with phenol reagent. J. Biol. Chem. 193: 265275.

Lucchi, M. L., R. Bortolami, and E. Callegari (1974) Fine structure of intrinsic eye muscles of birds: Development and postnatal changes. J. Submicrosc. Cytol. 6: 205-218.

Meriney, S. D., G. Pilar, M. Ogawa, and R. Nuñez (1987) Differential neuronal survival in the avian ciliary ganglion after chronic acetylcholine receptor blockade. J. Neurosci. 7: 3840-3849.

Nakano, K. E., and H. Nakamura (1985) Origin of the irideal striated muscle in birds. J. Embryol. Exp. Morphol. 88: 1-13.

Narayanan, Y., and C. H. Narayanan (1981) Ultrastructural and histochemical observations in the developing iris musculature in the chick. J. Embryol. Exp. Morphol. 62: 117-127.

Nishi, S. (1974) Ganglionic transmission. In The Peripheral Nervous System, J. I. Hubbard, ed., pp. 225-266, Plenum, New York.

Nuñez, R., G. Pilar, and K. Vaca (1980) Muscarinic-nicotinic changes in the cholinergic receptors involved in iris activation during development. Soc. Neurosci. Abstr. 8: 338.

Nuñez, R., R. Pilar, and I. McLennan (1982) Muscarinic and nicotinic receptors in the same striated muscle fiber are independently regulated. Soc. Neurosci. Abstr. 8: 338.

Pilar, G., and L. Landmesser (1972) Axotomy mimicked by localized colchicine application. Science 177: 1116-1118.

Pilar, G., and P. Vaughan (1969a) Electrophysiological investigations of the pigeon iris neuromuscular junctions. Comp. Biochem. Physiol. 29: $51-72$.

Pilar, G., and P. Vaughan (1969b) Mechanical responses of the pigeon iris muscle fibers. Comp. Biochem. Physiol. 29: 73-87.

Pilar, G., and P. C. Vaughan (1971) Ultrastructure and contractures of the pigeon iris striated muscle. J. Physiol. (Lond.) 19: 253-266.

Pilar, G., L. Landmesser, and L. Burstein (1980) Competition for survival among developing ciliary ganglion cells. J. Neurophysiol. 43: 233-254.

Pilar, G., J. Tuttle, and K. Vaca (1981) Functional maturation of motor nerve terminals in the avian iris: Ultrastructure, transmitter metabolism and synaptic reliability. J. Physiol. (Lond.) 321:175-193.

Pittman, R., and R. Oppenheim (1978) Neuromuscular blockade in creases motoneurone survival during normal cell death in the chick embryo. Nature 271: 364-366.

Redman, R. S., L. R. Sweney, and S. T. McLaughlin (1980) Differentiation of myoepithelial cells in the developing rat parotid gland. Am. J. Anat. 158: 299-320.

Reger, J. F. (1966) The fine structure of iridial constrictor pupillae muscle of Alligator mississippiensis. Anat. Rec. 155: 197-215.

Romanoff, A. L. (1960) The Avian Embryo, pp. 406, Macmillan, New York.

Seliger, H. H. (1962) Direct action of light in naturally pigmented muscle fibers. I. Action spectrum for contraction in eel iris sphincter. J. Gen. Physiol. 46: 333-342.

Sims, S. M., J. J. Singer, and J. V. Walsh (1985) Cholinergic agonists suppress a potassium current in freshly dissociated smooth muscle cells of the toad. J. Physiol. (Lond.) 367: 503-529.

Vaca, K., R. Nuñez, and G. Pilar (1980) Neural control of acetylcholine receptor and contraction in avian iris. Soc. Neurosci. Abstr. 6: 99 .

Van Oehme, H. (1969) Der Bewegungsapparat der Vogeliris (eine vergleichende morphologisch-funktionelle Untersuchung). Zool. Jb. Anat. Bd. 86: 96-128.

Yamamura, H. I., and S. H. Snyder (1974) Muscarinic cholinergic receptor binding in the longitudinal muscle of the guinea pig ileum with ${ }^{3} \mathrm{H}$-quinaclidinyl benzylate. Mol. Pharmacol. 10:861-867.

Young, J. A., and E. W. Van Lennep (1977) Morphology and physiology of salivary myoepithelial cells. Int. Rev. Physiol. 12: 105-125. 